Check for updates

Cite this: RSC Adv., 2017, 7, 23615

Received 19th December 2016 Accepted 30th March 2017

DOI: 10.1039/c6ra28392f

rsc.li/rsc-advances

\section{Polyolefin/graphene nanocomposites: a review}

\begin{abstract}
Sandeep N. Tripathi, (D) *a G. S. Srinivasa Rao, ${ }^{a}$ Ajit B. Mathur ${ }^{\mathrm{b}}$ and Rakshvir Jasrab
Polymeric materials reinforced with nanofillers continue to fulfill the worldwide demand for alternative materials with low cost and better physico-mechanical properties. These materials are prepared by mixing polymers with nanofillers (e.g. layered silicates, metal oxides, carbon nanotubes (CNTs) and graphene) using in situ or melt blending techniques for improved physico-mechanical properties. Among all the nanofillers, CNTs and graphene have emerged as subjects of tremendous scientific interest and have attracted a great deal of attention from across several disciplines in recent years. Among the nanofillers, graphene has shown very good electrical, thermal, mechanical and gas barrier properties in combination with polyolefins. The present review is an overview of polyolefin/graphene based composites, especially of polypropylene (PP) and polyethylene (PE), with special emphasis on their methods of preparation, properties and potential applications.
\end{abstract}

\section{Introduction}

Polymer nanocomposites (PNCs) are multiphase materials, which consist of a polymer or copolymer having nanoparticles or nanofillers (having dimension of 1-50 nm) dispersed in the polymer matrix, significantly affecting different physical properties. The majority of the research has focused on polymer nanocomposites based on nanofillers such as metal oxides, CNTs, carbon black (CB) and layered silicates to achieve

${ }^{a}$ Reliance Research \& Development Centre, Reliance Corporate Park, Reliance Industries Limited, Ghansoli, Navi Mumbai-400701, India. E-mail: sandeep.n. tripathi@ril.com; sandeepchemica@gmail.com; Tel:+912244751367; +917738074394 ${ }^{b}$ Research \& Development Centre, Vadodara Manufacturing Divison, Reliance Industries Limited, Vadodara-391346, India improved mechanical, thermal, electrical and gas barrier properties. $^{\mathbf{1 - 3}}$ Recently, graphene has emerged as the most promising nanofiller, due to its extraordinary physical properties, which has opened a new class of polymeric nanomaterials.

Graphene, a new allotrope of carbon is a two dimensional, one atom thick planer sheet composed of $\mathrm{sp}^{2}$ hybridised carbon atoms arranged in a crystal honeycomb lattice and is the thinnest known material in the universe. ${ }^{4,5}$ It is one of the special allotropes of carbon, which can be seen as the building block of all graphitic forms (Fig. 1); it can be stacked up into graphite (3D), rolled up into carbon nanotubes (1D) and wrapped up into fullerene (0D). Defect free graphene has outstanding physicochemical properties with large surface area and an optical transmittance of $\sim 98 \%,{ }^{4}$ high thermal and electrical

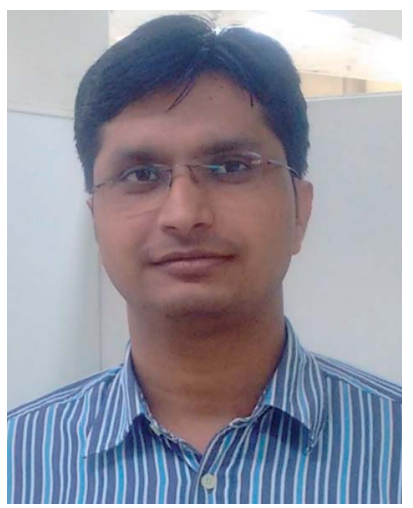

Dr Sandeep N. Tripathi currently works as Research Scientist at the Reliance Research and Development Centre, Reliance Industries Limited, Mumbai, India. He received his Ph.D. from the Centre for Polymer Science and Engineering, Indian Institute of Technology Delhi, New Delhi, and his M.Sc. in Chemistry from D.D.U. Gorakhpur University, Gorakhpur (India). He has 10 research publications in international journals and has participated in various national and international conferences. His area of research is mainly focused on polymer nanocomposites based on carbon nanofillers, and their specialty applications.

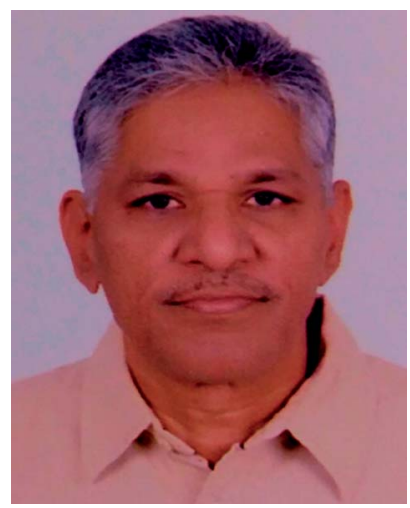

Dr G. S. Srinivasa Rao is presently the Assistant Vice President at the Reliance Research \& Development Centre, Reliance Industries Limited, Mumbai, India. He obtained his Ph.D. from the Indian Institute of Chemical Technology (IICT), Hyderabad. He has 28 years of research experience in polymers and petrochemicals, especially in the area of polyolefins, elastomers, additives and their synthesis, reactive processing and new product development. He has over 30 patents and 35 publications in national and international journals of repute, and has received four national awards. 


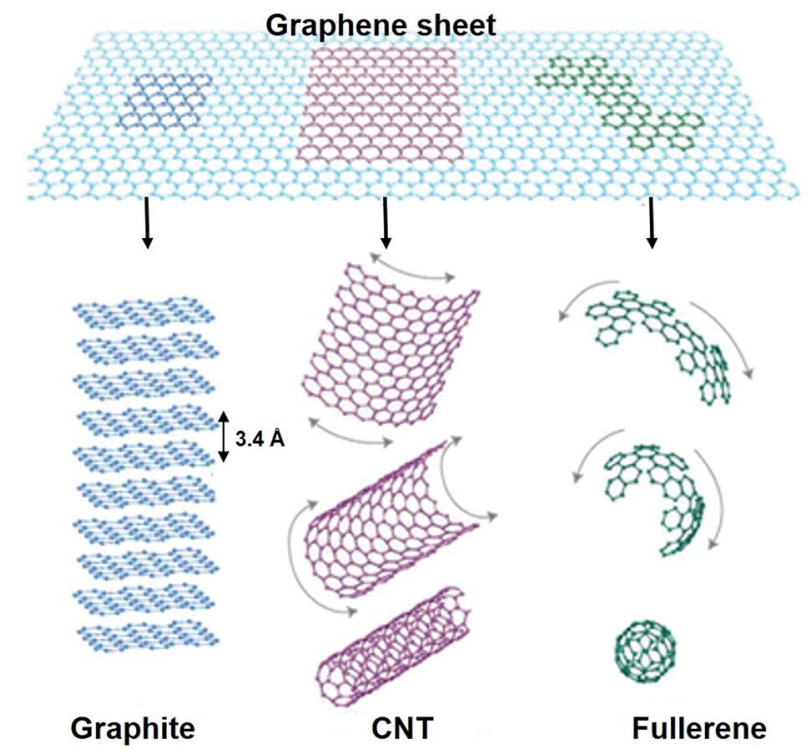

Fig. 1 Representation of graphene sheet: mother of all graphitic allotropes (reproduced with permission from ref. 4 copyright 2007 Nature Publishing Group).

conductivity and high mechanical properties. ${ }^{5}$ These extraordinary properties of graphene make it a promising nanofiller in the field of polymer nanocomposites. It has also shown great potential for application in electronics, photo-catalysis, sensors, medicine and solar cells. ${ }^{6-10}$

Polyolefin nanocomposites based on nanofillers offer opportunities for the improvement of polyolefins (POs) with relatively small amounts of nanofiller concentration. POs such as polyethylene and polypropylene are the most abundant synthetic polymers, having the largest tonnage in the world, with respect to their production. It was estimated that more than $60 \%$ of produced polyolefins (PE, PP) have been introduced into the market, whereas only $23 \%$ of other thermoplastics have been used for compounding purposes. ${ }^{11}$ POs are produced by the polymerization of ethylene, propylene alone or with other olefin monomers like butene- 1 and hexene- 1 using Ziegler-Natta and other catalysts. Depending on their density and chain branching, polyethylenes (PEs) are classified into different categories; e.g. low density polyethylene (LDPE), linear LDPE, high density polyethylene (HDPE), ultrahigh molecular weight polyethylene (UHMWPE) and polypropylenes (PPs) are classified as isotactic, syndiotactic and atactic, based on their stereo-regularity. Polyolefins became popular due to their low cost, recyclability, good processability, non-toxicity and biocompatibility. POs have a wide range of applications in orthopaedic implants, durable equipment automobile parts, consumer goods and industrial machinery. However, for advanced/engineering applications, there is the need to improve the physico-chemical and mechanical properties of polyolefins by introducing new functionalities, adding nanofillers to the matrix, modifying the polymer matrix and synthesizing a new type of polyolefin such as disentangled ultrahigh molecular weight polyethylene (DUHMWPE). ${ }^{\mathbf{2}}$ Recently, graphene has been investigated as a promising nanofiller for POs. Several articles are available where graphene has been used for the reinforcement of polyolefins due to its extraordinary physical properties..$^{\mathbf{1 3}, 14}$

Several review articles are available on graphene based polymer nanocomposites, which address the production and improved properties of polymer graphene composites. ${ }^{15-18}$ The present review is mainly focused on graphene based polyolefin nanocomposites and will not discuss other polymer graphene composites. The following is a quick review of methods of preparation of graphene, its derivatives and their physical properties. In addition, current progress on polyolefin (e.g. LDPE, LLDPE, HDPE, UHMWPE and PP) nanocomposites based on graphene and their improved properties are also reviewed.

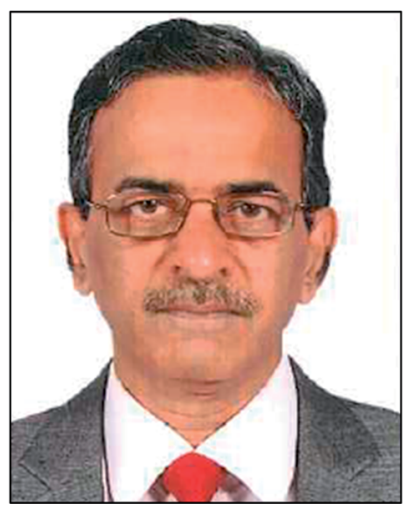

Dr Ajit B. Mathur is Vice President $(R \& D)$ at Reliance Industries Limited (RIL), India. He has over 40 years of experience in Polymer Research. His current portfolio includes polymer processing, specialty polymeric materials, biopolymers, polymer additives, niche product development, reactive processing and structure-property relationships. He has successfully contributed to translating various laboratory studies to the pilot level and production scale. Previously, he worked for 10 years with the Central Institute of Plastics Engineering and Technology as Administrative Head. He has authored one book, 40 patents and 80 research and conference papers. He is also a recipient of prestigious National Awards for his contributions to polymer catalysts and processes.

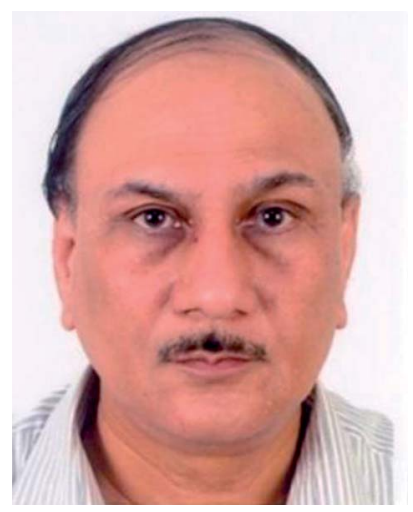

Dr Raksh Vir Jasra, FNAE, Ph.D. from the Indian Institute of Technology (IIT) Delhi, New Delhi has 35 years of research experience in the area of chemicals and petrochemicals. He has written more than 280 research articles and 100 granted patents. Dr Jasra, Fellow of the Indian National Academy of Engineering is a nationally and internationally recognized scientist with 15 awards to his credit. He joined Reliance in 2008 as Head of the Research \& Development Centre, Vadodara and is working on Petrochemicals research. 
Finally, the potential applications and future scope of this exciting new class of polyolefin/nanocomposites are discussed.

\section{Synthesis of graphene oxide (GO)/ reduced graphene oxide (RGO)}

Graphene was first isolated by Novoselov et al. in 2004 via micromechanical exfoliation using the "scotch tape" method; ${ }^{19}$ since then, a number of methods have been reported for the synthesis of graphene, such as chemical vapour deposition (CVD) ${ }^{20,21}$ arc discharge, ${ }^{22,23}$ epitaxial growth on SiC, ${ }^{24,25}$ unzipping carbon nanotubes ${ }^{26-28}$ and chemical reduction of graphite oxide. ${ }^{29,30,34}$ All the methods have their own advantages and disadvantages, such as micromechanical exfoliation; e.g. the scotch tape method offers quality graphene for electronic application, but gives low yield. CVD and epitaxial growth of graphene on silicon substrate produces bulk quantities of graphene, but it is very costly and requires high temperature. Unzipping of carbon nanotubes provides high quality graphene nanoribbons, but takes more time. These methods are very attractive for the synthesis of graphene for fundamental studies and electronic applications, but are not suitable for polymer nanocomposites, which require graphene in bulk quantities as a nanofiller.

\subsection{Chemical vapour deposition (CVD) method}

The CVD method involves the thermal decomposition of hydrocarbon gases, e.g. methane at high temperature $\left(\sim 1000^{\circ} \mathrm{C}\right)$ and low pressure, and its deposition on a substrate in a furnace provides a straight forward method for the synthesis of graphene. A number of different hydrocarbons, catalysts and inert gas combinations have been used by several researchers in the past for the growth of graphene on different substrates such as $\mathrm{SiO}_{2},{ }^{31}$ $\mathrm{Si}_{3} \mathrm{~N}_{4}$ (ref. 32) and $\mathrm{MgO}^{33}$ by the CVD technique. However, almost all the reported CVD techniques are based on metal-catalysed growth, which is complicated and needs skilled post growth techniques to be employed for the removal of these metal catalysts, which hamper the use of the graphene in electronic devices.

\subsection{Reduction of graphite oxide}

Currently, the most viable method for the bulk production of graphene for nanofiller applications in polymer nanocomposites is the exfoliation and reduction of graphite oxide, which is prepared by the oxidation of graphite. The synthesis of graphite oxide is more than 150 years old; its first synthesis was reported by Brodie ${ }^{35}$ in 1859. Later on, graphite oxide was prepared by using the Staudenmaier ${ }^{36}$ and Hummers ${ }^{137}$ methods, where graphite was oxidized to graphite oxide using strong oxidative reagents such as $\mathrm{KClO}_{3}, \mathrm{KMnO}_{4}$ and $\mathrm{NaNO}_{3}$ in the presence of concentrated $\mathrm{H}_{2} \mathrm{SO}_{4}, \mathrm{HNO}_{3}$, or a mixture of both. Among all the other methods reported for the preparation of graphite oxide, the Hummers' method is the most popular one in which $\mathrm{KMnO}_{4}$ and $\mathrm{NaNO}_{3}$ are used as oxidizing agents for the oxidation of graphite in the presence of concentrated $\mathrm{H}_{2} \mathrm{SO}_{4}$, depending on the requirement of the extent of oxygen functionalities (Fig. 2). Choudhary et $a{ }^{38}$ also prepared graphite oxide from graphite by using the modified Hummers' method.

Graphite is composed of stacked graphene sheets with an interlayer spacing of $3.4 \AA$ and in the same way, graphite oxide is composed of graphene oxide (GO) sheets stacked with an interlayer spacing of $8.4 \AA^{38}{ }^{38}$ Based on theoretical and experimental studies, the structure of graphene oxide contains a number of oxygen functionalities such as hydroxyl, carboxyl, epoxide and carbonyl groups. The Lerf-Klinowski model ${ }^{39,40}$ proposed the most likely description of the graphite oxide structure, where graphite oxide contains pristine aromatic "islands" separated from each other by aliphatic regions, which contain oxygen functionalities such as hydroxyl, carbonyl, epoxide and double bonds, as shown in Fig. 2. Conversion of graphite to graphite oxide, followed by exfoliation leads to the large scale production of graphene oxide, also known as functionalized graphene, which can be readily dispersed in water and organic solvents. Graphene oxide (GO) is electrically insulating and thermally unstable; therefore, to restore its electrical and thermal properties, its reduction is necessary. A number of methods are available for the exfoliation and reduction of graphite oxide to reduced graphene oxide (Fig. 3). The term "reduced graphene" is used because the complete reduction of graphene oxide to graphene does not occur.

There are basically two methods available for the exfoliation and reduction of graphite oxide to reduced graphene oxide.

2.2.1 Chemical reduction of graphite oxide. Chemically reduced graphene oxide (RGO) was prepared by a stable colloidal dispersion of graphite oxide followed by the reduction of exfoliated graphite oxide using reducing agents. Stable dispersion of GO can be obtained by exfoliation of graphite oxide via ultrasonication in water or alcohol. A number of reducing agents are used for the reduction of GO to RGO such as hydrazine hydrate ${ }^{30,31}$ (Fig. 4), dimethyl hydrazine, ${ }^{42}$ sodium borohydride followed by hydrazine ${ }^{43}$ hydroquinone ${ }^{44}$ and lithium aluminium
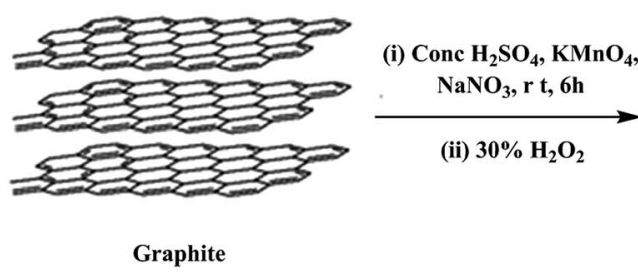

(ii) $30 \% \mathrm{H}_{2} \mathrm{O}_{2}$

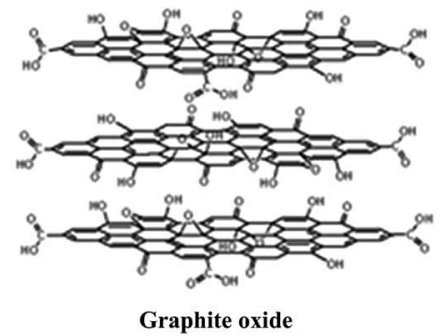

Graphite oxide

Fig. 2 Schematic representation of the oxidation of graphite to graphite oxide. 


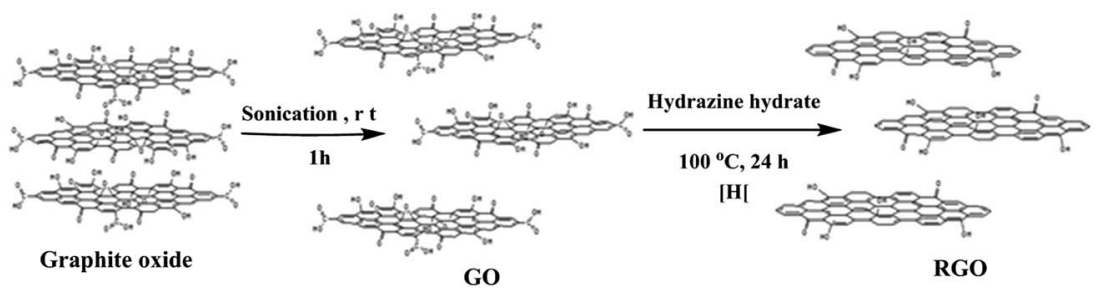

Fig. 3 Schematic representation of reduction of GO to RGO.

hydride. ${ }^{45}$ Stankovich et al. ${ }^{41}$ have proposed the following mechanism for the formation of RGO from graphite oxide, which shows that the reduction of GO restores the $\mathrm{sp}^{2}$ character of

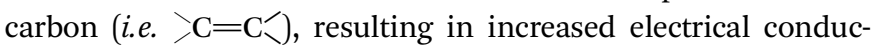
tivity of RGO.
Thermal reduction methods have one advantage over the chemical reduction of graphite oxide to produce thermally reduced graphene oxide (TRG) sheets, i.e. there is no need for solvent for the dispersion of graphite oxide. TRG has the $\mathrm{C}: \mathrm{O}$ ratio of $\sim 10: 1$, as compared to $2: 1$ for graphite oxide, ${ }^{48}$ which

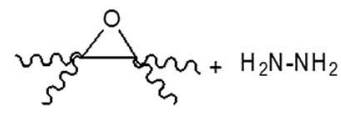<smiles>CCCCC(C)C(C)C(=O)NN</smiles>

2.2.2 Thermal reduction of graphite oxide. Thermal exfoliation and reduction of graphite oxide to thermally reduced graphene oxide (TRG) can be achieved by the rapid heating of dry graphite oxide for a very short period (30 s) at high temperature $\left(\sim 1000^{\circ} \mathrm{C}\right)$ under inert atmosphere..$^{46-48}$ Exfoliation of graphite oxide to GO takes place due to the pressure generated by the evolved $\mathrm{CO}_{2}$, which occurs due to the decomposition of epoxy, carboxyl and hydroxyl groups of GO that exceeds van der Waals forces holding GO sheets to each other. can be increased to $660: 1$ via heating at higher temperature $\left(1500{ }^{\circ} \mathrm{C}\right)$, or for longer time. ${ }^{49}$

\section{Properties of graphene}

Graphene has exceptionally high material properties, very close to their theoretical limits, such as electrical and thermal conductivity, strength, stiffness and low density. Graphene is the only allotrope of carbon in which each single atom is

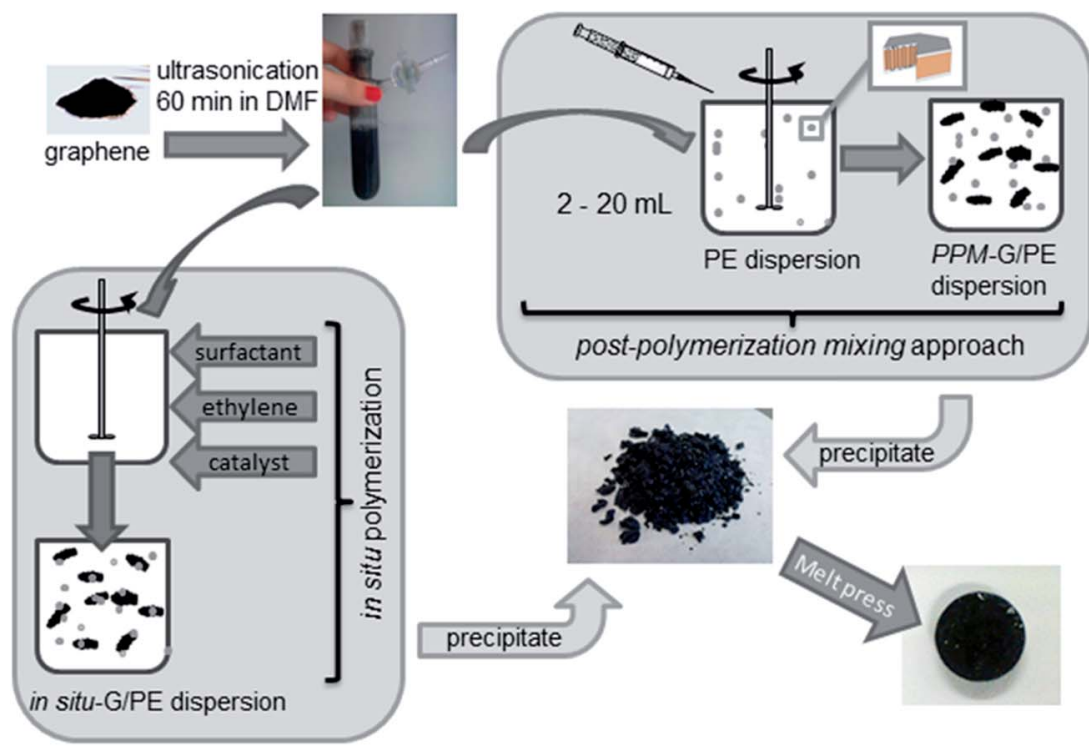

Fig. 4 Preparation of PE/graphene composites by in situ polymerization, post polymerization mixing and precipitation methods (reproduced with permission from ref. 58 copyright 2014 American Chemical Society). 
exposed for chemical reaction from both sides, which is attributed to its 2D structure. In addition, various types of defects occur in graphene due to its modification increasing its chemical reactivity.

Graphene is a zero-band gap semiconductor with remarkably high electron mobility at room temperature, having reported values of $\sim 15000 \mathrm{~cm}^{2} \mathrm{~V}^{-1} \mathrm{~s}^{-1}$. The electron mobility in graphene is independent of temperature between $10 \mathrm{~K}$ and $100 \mathrm{~K}$, which is ascribed to its defect scattering mechanism. Scattering by the acoustic phonons of graphene intrinsically limits the room temperature mobility to $200000 \mathrm{~cm}^{2} \mathrm{~V}^{-1} \mathrm{~s}^{-1}$, 50 which is attributed to the two-dimensional nature of graphene. In addition, the charge carriers can travel through graphene without scattering, which results in ballistic transport. Single layer graphene has a very high electrical conductivity value of $\sim 6000 \mathrm{~S} \mathrm{~cm}^{-1},{ }^{51}$ where chirality is not a limiting factor in its conductivity as in the case of CNTs. The impressive mechanical properties of graphene originate from its geometrical architecture, i.e. $\mathrm{sp}^{2}$ hybridized carbon atoms with $\mathrm{C}-\mathrm{C}$ bond length $0.142 \mathrm{~nm}$. Graphene is one of the strongest materials ever discovered, with a breaking strength 100 times greater than a film of steel of the same thickness. ${ }^{52}$ It has a Young's modulus of $1 \mathrm{TPa}$ and ultimate tensile strength of $130 \mathrm{GPa},{ }^{53}$ which is measured by the nanoindentation using atomic force microscopy.

The specific heat and thermal conductivity (TC) of graphene is determined by the phonons, which are the elastic waves propagated in graphene lattice. The thermal conductivity of graphene is isotropic. Graphene is known to be a perfect thermal conductor with thermal conductivity value at room temperature of $5000 \mathrm{~W} \mathrm{~m}{ }^{-1} \mathrm{~K}^{-1},{ }^{54}$ which is much higher than the thermal conductivity of other carbon structures such as carbon nanotubes, graphite and diamond. Graphite, which can be prepared by restacking graphene sheets and the $3 \mathrm{D}$ version of graphene, shows a thermal conductivity of $\sim 1000 \mathrm{~W} \mathrm{~m}^{-1} \mathrm{~K}^{-1}$, i.e. five times smaller than graphene. The study of thermal conductivity in graphene can have important applications in graphene-based electronic devices. ${ }^{51}$

In addition to these properties, graphene has an extremely high surface area of $2630 \mathrm{~m}^{2} \mathrm{~g}^{-1}$ (theoretical limit), and gas impermeability, ${ }^{55}$ which indicates that graphene has great potential for improving gas barriers, electrical, mechanical and thermal properties of matrix polymers in polymer nanocomposites. The present article is focused on polyolefin nanocomposites based on graphene and its derivatives.

\section{Polyolefin/graphene nanocomposites}

The most essential step in polymer nanocomposites is the compatibility and dispersion of nanofillers in the polymer matrix. A well dispersed state ensures maximum reinforcement, which will affect the neighbouring polymer chains and consequently, the properties of the whole matrix. Therefore, large efforts have been concentrated on achieving a homogeneous and well-dispersed system by developing either covalent or non- covalent functionalization of the filler surface. The earlier reports on polymer composites with exfoliated graphite fillers emerged from studies on the intercalation chemistry of graphite (GIC). In 1958, it was discovered that alkali metal-GICs could initiate the polymerization of ethylene. ${ }^{56}$ In 1993 Bunnell et al. ${ }^{57}$ proposed the production of polymer nanocomposites by incorporating graphite nanoplatelets (derived from GICs exfoliated either by shear grinding or thermal treatment) as fillers, where they suggested that with $20 \mathrm{wt} \%$ incorporation of graphite flakes in polyethylene or polypropylene, the stiffness of the finished product approached that of aluminium. However, it was not until 2000 that a detailed study of the morphology and properties of an exfoliated graphite nanocomposite was published. The discovery of graphene in 2004 (ref. 19) has opened up new method of incorporation in polymer matrices.

\section{Method of preparation of polyolefin/graphene composites}

In order to facilitate the industrial fabrication and application of graphene based polymer composites, the direct use of RGO or TRG as fillers to prepare polymer composites is preferred. The effective utilization of graphene composites strongly depends on the homogeneous dispersion of graphene and the interfacial interaction between the polymer matrix and graphene. Hence, to achieve high degree of graphene dispersion in polyolefins during processing without affecting the properties, three different techniques may be used: in situ polymerization, solvent blending and melt processing. In addition to polyolefins, various other types of matrices such as poly(methyl methacrylate), polyethylene glycol, polyamide, epoxy resins, poly(ethylene terephthalate), polystyrene etc. have also been used to prepare polymer/graphene nanocomposites for improved electrical, thermal and mechanical properties. Herein, various methods of preparation and properties of polyolefin/graphene composites such as in situ polymerization, solvent blending and melt blending methods are discussed.

\subsection{In situ polymerization}

In situ polymerization is a convenient processing technique, and has been extensively used for the preparation of polymer nanocomposites based on graphene derivatives such as GO, RGO or TRG, which involves the incorporation of graphene derivatives during the polymerization of monomer to improve the dispersion between two phases. The main advantage of this method is that it enables monomers present in and out of the graphene interlayers to polymerize to form polymer nanocomposites in which the graphene platelets are delaminated at the nano level. In situ polymerization is very important for the preparation of insoluble and thermally unstable polymers, which cannot be processed by solution or melt compounding. Depending on the required molecular weight and molecular weight distribution of polymers, chain transfer, free radical, anionic and ring-opening metathesis polymerizations can be used for the in situ polymerization technique. Although in situ polymerization is a very attractive technique for well dispersed 
graphene composites, there are few reports available on LDPE/ graphene composites.

Mecking et al. ${ }^{58}$ prepared polyethylene/TRG nanocomposites using in situ polymerization of ethylene in an aqueous solution in the presence of surfactant (Fig. 4) and by the post polymerization mixing (PPM) approach, and compared it with commercial graphene. It was found that PE/TRG composites show a lower percolation threshold ( $2 \mathrm{wt} \%)$ than commercial samples (20 wt\%).

Ultra high molecular weight polyethylene (UHMWPE) is a unique class of polyethylene produced by the polymerization of ethylene monomer in the presence of Ziegler-Natta catalyst. Sarma et al. have reported the synthesis of $\mathrm{UHMWPE}^{59}$ using single site catalyst and disentangled ultra-high molecular weight polyethylene (DUHMWPE) new polymer ${ }^{60}$ by a novel non-cryogenic process under controlled conditions with low entanglements. Rastogi et al. ${ }^{61}$ have also reported the synthesis of low entangled UHMWPE, also called disentangled UHMWPE, which can be processed in the solid-state below melt temperature in the form of the uniaxial drawn tapes and films with higher tensile strength and tensile modulus. UHMWPE has a wide spectrum of applications as synthetic ice, biomedical applications. ${ }^{\mathbf{6 2 , 6 3}}$ However, the increasing demand for applications with increased mechanical as well as electrical properties of UHMWPE has led to the application of other techniques for preparation of reinforced composites with enhanced mechanical and electrical properties.

The in situ polymerization process is very useful in the preparation of UHMWPE graphene nanocomposites. Ramazani et al. ${ }^{64}$ reported the synthesis of UHMWPE composites using GO supported Ziegler-Natta catalyst. They used mono and bisupported ZN catalyst using magnesium ethoxide and GO as catalyst support. Mulhaupt et al. ${ }^{65}$ synthesized UHMWPE graphene composites in the presence of single site chromium catalyst supported on functionalized graphene (FG) using the polymerization filling technique (PFT), where the fillers are used as catalyst supports to enable polymer chain growth directly from the surface of nanofillers (Fig. 5).

PP has a variety of applications in automotive industries, packaging and labelling, textile industries (e.g. ropes, thermal wear and carpets made up of nonwoven fibers), stationery, and laboratory equipment. In spite of so many applications, PP has poor impact behaviour, shrinkage and relatively low stiffness at low temperature, which leads to replacement with engineering plastics. Therefore, several works have been carried out to

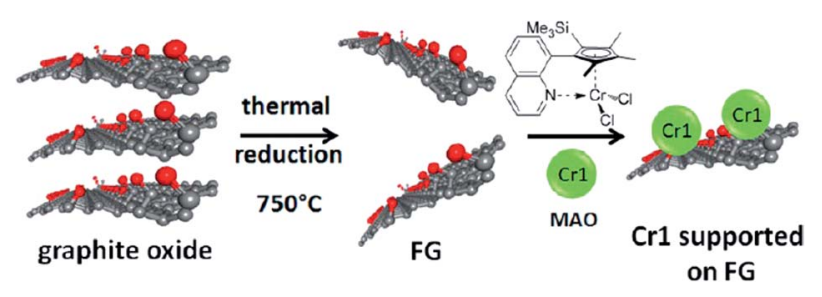

Fig. 5 Schematic representation of single-site chromium catalyst (Cr1) supported on functionalized graphene (FG) (reproduced with permission from ref. 65 copyright 2012 American Chemical Society). reinforce PP using $\mathrm{CNTs}^{66}$ and graphene ${ }^{67}$ to improve the physical, mechanical and physicochemical properties such as fracture toughness, impact strength, electrical and thermal conductivity, and flammability of polypropylene.

Huang et al. ${ }^{68}$ reported $\mathrm{PP} / \mathrm{GO}$ nanocomposite preparation using in situ ZN polymerization. First, the GO supported catalyst system based on titanium and magnesium metal $\left(\mathrm{TiCl}_{4} / \mathrm{BuMgCl}\right)$ was prepared, and subsequent in situ polymerization of propylene led to the uniform dispersion of GO sheet in the PP matrix, which had better dispersion and exfoliation of the graphene sheet (Fig. 6). The prepared PP/GO composite exhibited electrical conductivity of $0.3 \mathrm{~S} \mathrm{~m}^{-1}$ at $4.9 \mathrm{wt} \% \mathrm{GO}$ concentration.

Many reports are available on in situ polymerized PP/ graphene nanocomposites with better compatibility and dispersion of graphene sheets, along with improved physical properties. ${ }^{69-71}$ Dang et al..$^{72}$ synthesized a $\mathrm{PP} /$ reduced graphene oxide composite by using latex technology, which involved the in situ reduction of GO in the PP latex and subsequent filtration (Table 1). Morphological studies by SEM and XRD revealed the homogeneous dispersion of RGO in the PP matrix, whereas near the percolation threshold concentration, its dielectric properties were also improved with increasing the concentration of RGO.

\subsection{Solution blending}

Solution blending is the most common method for preparing graphene/polymer composites, especially with higher molecular weight polymers, which involves mixing of graphene and matrix polymer in a suitable solvent. A typical solution blending involves three steps: dispersion of graphene in a suitable solvent, mixing with the polymer solution (at room temperature or elevated temperature) and recovery of the nanocomposite by precipitating or casting a film. Rigorous mixing of graphene with polymer in a solvent significantly enhances de-aggregation and dispersion of graphene in the polymer matrix. Solution based methods offer advantages of lower viscosities, which facilitate uniform mixing and better dispersion of graphene. One of the major disadvantages of this method is the use of large quantities of solvents and their evaporation.

Kuila et $a .^{73}$ have prepared LLDPE/graphene nanocomposites based on dodecyl amine-functionalized graphene (DA-G), using xylene as solvent, by the solution blending method. They observed the increased average crystallite size of the nanocomposites by X-ray analysis. However, the percentage of crystallinity was decreased due to the random interface. It was also found that the thermal stability and the crystallization temperature of the LLDPE/DA-G nanocomposites were increased as observed through TGA and DSC, respectively. The composites have also shown very good gas barrier properties for $\mathrm{O}_{2}$ and $\mathrm{N}_{2}$. HDPE has very good physical properties, but the incorporation of carbon nanomaterials will further enhance its overall properties like strength, thermal and electrical properties. Many reports are available related to the incorporation of graphene into the HDPE matrix using solution blending techniques. Asmatulu et $a .^{74}$ prepared recycled HDPE/graphene nanoflake composites by the solution blending method using 


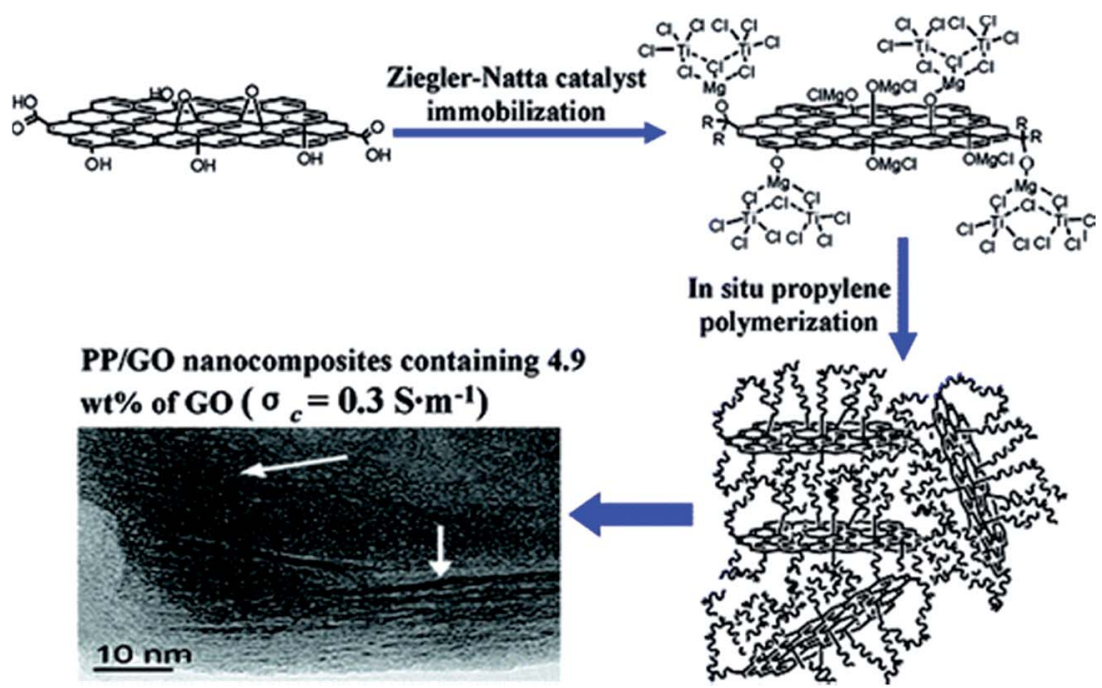

Fig. 6 Schematic of synthesis of PP/GO nanocomposites by in situ polymerization (reproduced with permission from ref. 68 copyright 2010 American Chemical Society).

Table 1 Polyolefin/graphene composites by in situ polymerization

\begin{tabular}{|c|c|c|c|c|c|c|}
\hline $\mathrm{PO} / \mathrm{G}$ composite & \multicolumn{3}{|l|}{ Graphene type/loading (wt\%) } & Solvent & Ref. & Remarks \\
\hline i-PP/GNS & GNS & 0.5 & 20.0 & Toluene & 67 & $\begin{array}{l}\text { Metallocene complex rac- } \\
\mathrm{Me}_{2} \mathrm{Si}(\mathrm{Ind})_{2} \mathrm{ZrCl}_{2} \text { and methyl } \\
\text { aluminoxane as cocatalyst for propylene } \\
\text { polymerization }\end{array}$ \\
\hline $\mathrm{PP} / \mathrm{GO}$ & GO & 0.96 & 4.9 & Hexane & 68 & $\begin{array}{l}\mathrm{TiCl}_{4} / \mathrm{BuMgCl} \text { catalyst supported on } \mathrm{GO} \\
\text { for polymerization of propylene in } \\
\text { hexane }\end{array}$ \\
\hline i-PP/graphene & Graphene & 0.1 & 2.0 & Xylene & 69 & $\begin{array}{l}\text { Complexation of } \mathrm{ZN} \text { catalysts onto } \\
\text { graphene sheets for propylene } \\
\text { polymerization }\end{array}$ \\
\hline
\end{tabular}

toluene as the solvent. The maximum of $8 \mathrm{wt} \%$ of graphene was incorporated to get improvement in the mechanical, thermal, and dielectric properties of the polymer nanocomposites as a function of graphene concentration. The surface hydrophobic properties were slightly increased at lower concentrations and then reduced at higher concentrations of graphene, due to increased surface smoothness.

Suner et $a l .{ }^{78}$ reported the synthesis of UHMWPE/GO nanocomposites using the ball milling technique by first dispersing graphene oxide in ethanol and blending with UHMWPE in the same dispersion of GO-ethanol mixture, followed by the ball milling of the slurry at $400 \mathrm{rpm}$. They observed the improved physical properties of the composites such as mechanical, thermal and wettability behaviour of the UHMWPE/GO nanocomposite. Rastogi et al. ${ }^{79}$ reported the synthesis of $\mathrm{D} /$ UHMWPE/reduced graphene oxide composites by the solvent blending method and they found improved rheological and electrical conductivities of UHMWPE and DUHMWPE composites. The composites were prepared via the solvent blending method using acetone, where GO was first dispersed in water followed by ultrasonication and simultaneously, polymer was dispersed in acetone and mixed with stirring. The resultant UHMWPE/GO composites were reduced at different temperatures of $160,180,200$ and $230{ }^{\circ} \mathrm{C}$ with hot pressing to restore the electrical conductivity of graphene, and finally the rheological responses of the two different composites were compared. Li et $a l .{ }^{80}$ reported the synthesis of the UHMWPE/ graphene nanosheet (GNS) composite using water/ethanol solvent assisted dispersion of GNS, followed by compression moulding at $200{ }^{\circ} \mathrm{C}$. They found a very low percolation threshold concentration of 0.07 vol\% (i.e. $\sim 0.15 \mathrm{wt} \%$ ) of GNS due to the formation of a $2 \mathrm{D}$ network with electrical 
conductivity value od $10^{-10} \mathrm{~S} \mathrm{~cm}^{-1}$ and max conductivity of $10^{-3} \mathrm{~S} \mathrm{~cm}^{-1}$ at $1.5 \mathrm{wt} \%$ GNS. Zhao et al. ${ }^{81}$ have also reported a similar type of study, which involves a two-step process for the UHMWPE graphene composite. First, graphene oxide was coated on UHMWPE then reduction of GO was carried out in situ. The resultant composite was moulded into a sheet by hot pressing at $200{ }^{\circ} \mathrm{C}$ to obtain composites with segregated structure, which exhibited a very low percolation threshold of 0.028 vol\% ( $0.06 \mathrm{wt} \%)$ with max conductivity value of $10^{-1} \mathrm{~S} \mathrm{~cm}^{-1}$ at $1.0 \mathrm{wt} \%$ RGO. Bhattacharyya et $a l .{ }^{82}$ synthesized UHMWPE/RGO nanocomposites using the solution blending method. The solvents used were dimethyl formamide (DMF) and orthodichlorobenzene (ODCB). Two methods were used to prepare the composite film: in one method, GO was dispersed and simultaneously reduced to RGO before the addition of polymer, whereas in the second method GO was reduced after the addition of polymer. Only $1 \mathrm{wt} \%$ of GO was used to compare the tensile strength and creep resistance of the UHMWPE composite in both processes.

There are more reports available on the preparation of UHMWPE/graphene and LLDPE/graphene composites to improve some of the properties, as given by Agarwal et al. ${ }^{62}$ for the nanotribological behaviour of graphene/UHMWPE composites, Wang et $a l .{ }^{83}$ for electrically conductive material using the electrostatic absorption method, Puértolas et al. ${ }^{84}$ for mechanical properties, chemical stability, wear resistance and biocompatibility (Table 2 ).

To overcome the challenge of the homogeneous dispersion of graphene in the polymer matrix, Fang et al. ${ }^{86}$ reported an eco- friendly approach to synthesize PP/graphene composites. They coated graphene with PP latex and subsequently, melt blending was carried out for graphene coated PP latex. Improved mechanical and thermal properties were observed at $1 \mathrm{wt} \%$ of graphene concentration. Guo et al. ${ }^{87}$ reported a solution (xylene) blending method for the preparation of $\mathrm{PP} /$ graphene nanoplatelets composites with improved thermal and electrical properties (conductivity and permittivity). They were able to incorporate $20 \mathrm{wt} \%$ of graphene nanoplatelets in the PP matrix with electrical percolation at $12 \mathrm{wt} \%$.

\subsection{Melt blending}

Melt processing is the preferred choice for the industrial applications, because of its low cost and simplicity, which facilitate large scale production for commercial applications. Melt processing basically involves melting of polymer pellets to form a viscous liquid and then the use of high shear force to disperse the nanofillers. Hence, it does not require any solvent for the dispersion of polymer and fillers. Melt processing is known to be environmental friendly because it uses commercial polymer and conventional blending techniques such as twin screw extrusion. Almost all the polyolefins are processed using the melt blending technique, except UHMWPE due to their high molecular weight and high viscosity (Table 3 ).

Kim et al. ${ }^{85}$ have prepared the LLDPE/TRG nanocomposite by melt blending of LLDPE and its functionalized analogue (amine, isocyanate and nitrile) produced by the ring opening polymerization technique with varying amounts of TRG. They

Table 2 Polyolefin/graphene composites by solution blending

\begin{tabular}{|c|c|c|c|c|c|c|}
\hline \multirow[b]{2}{*}{ Polymer matrix } & \multicolumn{3}{|c|}{ Graphene loading (wt\%) } & \multirow[b]{2}{*}{ Solvent } & \multirow[b]{2}{*}{ Ref. } & \multirow[b]{2}{*}{ Remarks } \\
\hline & Type & Min. & Max. & & & \\
\hline LLDPE & DA-f-G & 0.5 & 8.0 & Xylene & 73 & $\begin{array}{l}\text { LLDPE/DA-f-G nanocomposites for } \mathrm{O}_{2} \\
\text { and } \mathrm{N}_{2} \text { permeability of composite }\end{array}$ \\
\hline HDPE & $\begin{array}{l}\text { Graphene } \\
\text { nanoflakes }\end{array}$ & 1.0 & 8.0 & Toluene & 74 & $\begin{array}{l}\text { Improved mechanical, thermal, } \\
\text { electrical, and surface hydrophobic } \\
\text { properties }\end{array}$ \\
\hline UHMWPE & RGO & 1.0 & 1.0 & $\begin{array}{l}\text { DMF }: \text { ODCB } \\
(1: 4 \mathrm{v} / \mathrm{v})\end{array}$ & 82 & $\begin{array}{l}\text { Two methods were used: pre-reduction } \\
\text { and in situ reduction method in DME/ } \\
\text { ODCB for improved mechanical } \\
\text { properties }\end{array}$ \\
\hline UHMWPE & GNS & 0.14 & 1.5 & Water : ethanol & 80 & $\begin{array}{l}\text { For improved electrical conductivity and } \\
\text { percolation threshold conc. }\end{array}$ \\
\hline UHMWPE & RGO & 0.1 & 4.0 & Acetone & 79 & $\begin{array}{l}\text { DUHMPE and commercial UHMWPE } \\
\text { composites with graphene were } \\
\text { compared for electrical conductivity and } \\
\text { rheology }\end{array}$ \\
\hline UHMWPE & GNP & 0.1 & 1.0 & Acetone & 62 & $\begin{array}{l}\text { Tribological and nano-scratch behaviour } \\
\text { of the composite }\end{array}$ \\
\hline UHMWPE & RGO & 0.05 & 1.0 & $\begin{array}{l}\text { Water : ethanol } \\
(50: 1)\end{array}$ & 81 & $\begin{array}{l}\text { Improved electrical conductivity and very } \\
\text { low electrical percolation threshold } \\
\text { concentration }\end{array}$ \\
\hline PP latex & RGO & 0.02 & 0.5 & Water & 86 & $\begin{array}{l}\text { PP/RGO composites by latex technology } \\
\text { with an ultralow electrical percolation } \\
\text { threshold conc. }\end{array}$ \\
\hline PP & GNP & 5.0 & 20.0 & Xylene & 87 & $\begin{array}{l}\text { Improved rheological, thermal, and } \\
\text { electrical properties }\end{array}$ \\
\hline
\end{tabular}


Table 3 Polyolefin/graphene composites by melt blending

\begin{tabular}{|c|c|c|c|c|c|}
\hline \multirow[b]{2}{*}{ Polymer matrix } & \multicolumn{3}{|c|}{ Graphene type/loading (wt\%) } & \multirow[b]{2}{*}{ Ref. } & \multirow[b]{2}{*}{ Remarks } \\
\hline & Type & Min. & Max. & & \\
\hline XLPE & f-GO & 0.5 & 3.0 & 88 & $\begin{array}{l}\text { GO was functionalized by a hyper- } \\
\text { branched flame retardant material and } \\
\text { incorporated into the XLPE matrix for } \\
\text { improved flame retardancy }\end{array}$ \\
\hline LLDPE-f-Py & TRG & 0.5 & 3.0 & 89 & $\begin{array}{l}\text { LLDPE- } g \text {-amino methyl pyridine reacted } \\
\text { with LLDPE- } g \text {-MA }(0.5-1.0 \text { wt } \% \text { graft }) \text { in } \\
\text { the melt mixer before compounding with } \\
\text { TRG }\end{array}$ \\
\hline HDPE & PE- $g$-G & 0.1 & 0.6 & 75 & Improved mechanical properties \\
\hline PP & GNS & 0.1 & 3.0 & 91 & $\begin{array}{l}\text { Homogeneous dispersion with improved } \\
\text { mechanical, rheological and thermal } \\
\text { properties }\end{array}$ \\
\hline PP & $\mathrm{xGnP}$ & 10 & 50 & 92 & $\begin{array}{l}\text { Prepared using a twin-screw extruder for } \\
\text { improved thermal, rheological and } \\
\text { barrier properties as a function of } x \mathrm{GnP} \\
\text { loadings }\end{array}$ \\
\hline
\end{tabular}

found TRG well dispersed in functionalized LLDPE, compared to unmodified LLDPE showing phase separation morphology. Wang et $a .^{88}$ prepared a cross-linked polyethylene (XLPE) nanocomposite based on GO functionalization with hyperbranched flame retardant materials ( $N$-aminoethyl piperazine and di(acryloyloxyethyl)methylphosphonate) to enhance the flame retardancy as well as thermal stability of the resultant composites. They were able to incorporate up to $3 \mathrm{wt} \%$ of the $\mathrm{f}$ GO into the XLPE matrix. Kontopoulou et al. ${ }^{89}$ have reported a non-covalent compatibilization approach for the synthesis of LLDPE/TRG composites. Firstly, LLDPE- $g$-amino methyl pyridine reacted with LLDPE- $g$-MA (0.5-1.0 wt\% graft) in a melt mixer followed by compounding with $3 \mathrm{wt} \%$ TRG in microcompounder to improve the filler dispersion and mechanical/ thermal properties.

Song et $a .^{75}$ reported the preparation of HDPE/graphene composites by melt blending. In their approach, first they prepared polyethylene grafted on the surface of graphene (PE- $g$ G) by in situ polymerisation followed by melt blending with HDPE in a twin screw microcompounder for improved compatibility between polymer and graphene, which resulted in improved mechanical properties. Bai and $\mathrm{Wei}^{77}$ synthesized a highly exfoliated HDPE/graphene composite using a solid state shear milling technique and melt mixing of composite powder in a micro-compounder to get highly dispersed HDPE/ graphene composite with high mechanical performance.

Wang et al. ${ }^{90}$ studied the effect of functionalized graphene on the iPP matrix using the melt blending method. They used functionalized GO with 4,4'-diphenylethane diisocyanate and stearic acid to form functionalized graphene and then melt blending was carried out in a twin screw microcompounder to get the iPP/FG nanocomposite. FGs achieved good dispersion and strong interfacial adhesion with the iPP matrix, which enhanced the thermal and mechanical properties at low FGs loadings.

Achaby et al. ${ }^{91}$ reported the fabrication of $\mathrm{PP} /$ graphene nanosheet (GNS) nanocomposites by the melt blending method in a twin screw microcompounder. The GNS used here was prepared by chemical reduction of GO using hydrazine hydrate. They found that increasing the GNS content in the PP matrix enhanced the mechanical as well as thermal properties of the overall composite materials. Kalaitzidou et al. ${ }^{92}$ reported the preparation of PP nanocomposites based on exfoliated graphite nanoplatelets $(\mathrm{xGnP})$ as a reinforcement nanofiller using melt blending in the twin screw extruder, followed by injection moulding to generate samples of ASTM standards for testing. The PP/xGnP composite samples were investigated for their thermal, rheological and barrier properties as a function of xGnP loadings and the obtained properties were compared with the properties of polyacrylonitrile (PAN) composites based on carbon fibers, carbon black and nanoclay. Several other reports are also available on similar kind of studies on polypropylene/graphene nanocomposites ${ }^{93-95}$ using a twin screw extruder or micro-compounder for the improved physical properties (such as thermal, mechanical, rheological and electrical properties) of the PP matrix.

\section{Properties of polyolefin/graphene composites}

Incorporation of graphene into polymer matrices will significantly enhance the mechanical, electrical and thermal 
properties, which depend on various factors like processing techniques, type of graphene, aspect ratio and loading of graphene. Some processing conditions or methods that are good for one property may not be good for another, e.g. surface functionalized graphene generally enhances the mechanical properties but deteriorates the electrical properties of the nanocomposites such as GO/polymer composites. Thus, it is very important to optimize the various conditions to obtain the nanocomposites with desired properties. Since the discovery of graphene, many studies have been done to evaluate the mechanical, electrical and thermal properties of polymer/ graphene nanocomposites at different filler loadings and conditions.

\subsection{Mechanical properties of polyolefin/graphene composites}

With Young's modulus of 1 TPa and intrinsic strength of 130 $\mathrm{GPa}$, defect free graphene is the strongest and stiffest material ever discovered, ${ }^{4}$ which suggests that the incorporation of graphene into the polymer matrices can lead to significant enhancement in their mechanical properties. Some studies have reported significant improvement in the mechanical properties of polymers by the incorporation of a very small amount of graphene. Incorporation of carbon nanomaterials in polyolefins is expected to improve the mechanical properties as well as other physical properties of these matrices, which can be considered for many applications including interior and exterior automobile parts.

Kuila et al. ${ }^{73}$ studied the effect of dodecyl amine functionalized graphene (DA-G) on the mechanical properties of the LLDPE matrix by the solvent blending method. They found that an increase of $118 \%$ in storage modulus of nanocomposites at 8 wt\% of DA-G (from $134 \mathrm{MPa}$ to $293 \mathrm{MPa}$ at $50{ }^{\circ} \mathrm{C}$ ) is because graphene acts as a reinforcing filler, which significantly decreases the chain mobility of the LLDPE matrix. Asmatulu et $a l^{74}$ reported the improved mechanical properties of the HDPE/graphene composite. The ultimate tensile strength increased by $56 \%$ (at $4 \mathrm{wt} \%$ graphene) and $>100 \%$ in tensile modulus (from 200 to $450 \mathrm{MPa}$ ) at $1 \mathrm{wt} \%$ graphene loading, which could be attributed to the thickness of the graphene sheet (0.35-1 $\mathrm{nm})$ leading to high surface area and increased load transfer sites between the polymer matrix and filler. Achaby and Qaiss $^{76}$ compared the mechanical properties of HDPE/GNs and HDPE/MWCNTs nanocomposites prepared by melt blending. The tensile strength of the HDPE/graphene nanocomposite was $77 \%$ higher than the pure polymer at 3 $\mathrm{wt} \%$ of graphene, whereas an increase of $58 \%$ was found in the case of the corresponding nanotube nanocomposites at the same filler concentration. The tensile modulus of HDPE/ graphene and HDPE/MWCNT nanocomposites was enhanced by 87 and 57\%, respectively, as compared to virgin HDPE matrix. Yan et $a l .{ }^{96}$ reported the UHMWPE/GO composite with enhanced mechanical properties with good biocompatibility for application as artificial joints in the human body. They found that the composite with $0.5 \mathrm{wt} \%$ GO had the best tensile properties and good biocompatibility.
Milani et $a l .{ }^{69}$ also investigated the mechanical performance of isotactic polypropylene/graphene composites prepared by in situ metallocene polymerization. It was found that graphene nanosheets were uniformly dispersed in the polymer matrix and the modulus was enhanced from $1280 \mathrm{MPa}$ in the case of the neat polymer, to $1920 \mathrm{MPa}$ for iPP/graphene nanocomposites at a higher loading of graphene, i.e. $17.4 \mathrm{wt} \%$. Table 4 is the summary of other polyolefin/graphene composites. Achaby et al. ${ }^{91}$ reported an $\sim 37 \%$ increase in Young's modulus (from $1156 \mathrm{MPa}$ to $1577 \mathrm{MPa}$ ) and $15 \%$ increase in tensile strength at $0.5 \mathrm{wt} \%$ of graphene in PP/GNS composites prepared via melt compounding. Song et al. ${ }^{86}$ reported an $\sim 75 \%$ increase in yield strength (from 22 to $37 \mathrm{MPa}$ ) and an $~ 74 \%$ increase in Young's modulus (1002 MPa to $1760 \mathrm{MPa}$ ) for $\mathrm{PP} / \mathrm{graphene}$ composites prepared by first coating graphene using PP latex and then meltblending the coated graphene with PP matrix at $1.0 \mathrm{wt} \%$ of graphene, due to the effective external load transfer.

\subsection{Thermal properties of polyolefin/graphene composite}

Incorporation of graphene can significantly enhance the thermal transport properties of polymer/graphene nanocomposites, which extend their applications in printed circuit boards, connectors, thermal interface materials, heat sinks, power electronics, electric motors, generator, heat exchangers etc. Thermal properties of a composite are a very important factor in selecting processing conditions and the application area of the composite material. As discussed above, the thermal conductivity (TC) of monolayer graphene is in the range of $5000 \mathrm{~W} \mathrm{~m}{ }^{-1} \mathrm{~K}^{-1}$, Veca et al. ${ }^{97}$ and Yu et al. ${ }^{98}$ have independently reported up to 30 -fold increase $\left(0.2 \mathrm{~W} \mathrm{~m}^{-1} \mathrm{~K}^{-1}\right.$ to $6.44 \mathrm{~W} \mathrm{~m}^{-1}$ $\mathrm{K}^{-1}$ ) in thermal conductivity for the epoxy matrix by the incorporation of $60 \mathrm{wt} \%$ and $50 \mathrm{wt} \%$ of $\sim 2 \mathrm{~nm}$ thick graphite nanoplatelets via in situ polymerization, respectively. However, Asmatulu et al. ${ }^{74}$ found a $65 \%$ increase in thermal conductivity ( 0.42 to $0.64 \mathrm{~W} \mathrm{~m}^{-1} \mathrm{~K}^{-1}$ ) for recycled high density polyethylene (HDPE) composites prepared by melt processing at a similar loading of graphene nanoplatelets $(8.0 \mathrm{wt} \%)$, which shows that the orientation of graphene, the degree of exfoliation and interfacial interaction of the host polymer with the graphene surface have an influence on the thermal conductivity of the composites. Kontopoulou et $a .^{\mathbf{8 9}}$ prepared functionalized LLDPE/TRG composites and found $>150 \%$ increase in thermal conductivity ( 0.20 to $0.52 \mathrm{~W} \mathrm{~m}^{-1} \mathrm{~K}^{-1}$ ) at $3.0 \mathrm{wt} \%$ TRG, which could be attributed to the better exfoliation and formation of the TRG network inside the polymer matrix (Table 5).

Along with TC, the improvement in thermal stability and melting temperature of the host polymer matrix is another benefit expected from graphene reinforcement. Achaby et al. ${ }^{91}$ reported a $6{ }^{\circ} \mathrm{C}$ increase in melting temperature (from 164 to $170{ }^{\circ} \mathrm{C}$ ) and $9{ }^{\circ} \mathrm{C}$ increase in crystalline temperature (116 to 125 ${ }^{\circ} \mathrm{C}$ ) of the PP matrix at $3 \mathrm{wt} \%$ of graphene loading in $\mathrm{PP} /$ graphene nanocomposites. Guo et $a .^{87}$ have reported the increased thermal stability of the $\mathrm{PP} /$ graphene composite with the increase in degradation temperature from 259 to $295{ }^{\circ} \mathrm{C}$ at 15 wt\% graphene loading. Qiu et al. ${ }^{90}$ compared the thermal stability of iPP nanocomposites based on stearic acid 
Table 4 Mechanical properties of polyolefin/graphene composites

\begin{tabular}{|c|c|c|c|c|c|c|c|}
\hline $\begin{array}{l}\text { Polymer } \\
\text { matrix }\end{array}$ & $\begin{array}{l}\text { Graphene }^{a} \\
\text { (wt\%) }\end{array}$ & $\begin{array}{l}\text { Method of } \\
\text { preparation }\end{array}$ & \multicolumn{2}{|c|}{ Tensile modulus (MPa) } & $\begin{array}{l}\text { Tensile strength } \\
\text { (MPa) \% increase }\end{array}$ & $\begin{array}{l}\text { Strain at } \\
\text { break (\%) }\end{array}$ & Ref. \\
\hline LLDPE & DA-f-G (8.0) & Solution & $1046^{b}$ & $1582^{b}(51)$ & NA & NA & 73 \\
\hline LLDPE- $g$-Py & TRG (3.0) & Melt & 90 & $155(72)$ & NA & $\sim 20$ & 85 \\
\hline HDPE & GNS (1.0) & Solution & 200 & $450(125)$ & NA & NA & 74 \\
\hline iPP & GNS (17.4) & In situ & 1280 & $1920(50)$ & No change & 30 & 70 \\
\hline PP & EGP-PP latex (1.0) & Melt & 1002 & $1760(75)$ & 75 & NA & 86 \\
\hline PP & GNS (3.0) & Melt & 1155 & $2315(100)$ & 81 & NA & 91 \\
\hline iPP & TRG (10.0) & Melt & 980 & $1500(53)$ & NA & -99 & 93 \\
\hline
\end{tabular}

${ }^{a}$ Graphene wt\% at which maximum mechanical property achieved. ${ }^{b}$ Obtained from dynamic mechanical analysis.

Table 5 Thermal conductivity (TC) of polyolefin/graphene composites

\begin{tabular}{llllll}
\hline & & & \multicolumn{2}{l}{ TC $\left(\mathrm{W} \mathrm{m}^{-1} \mathrm{~K}^{-1}\right)$} & \\
\cline { 5 - 6 } $\begin{array}{lllll}\text { Polymer } \\
\text { matrix }\end{array}$ & $\begin{array}{l}\text { Graphene }^{a} \\
(\mathrm{wt} \%)\end{array}$ & $\begin{array}{l}\text { Method of } \\
\text { preparation }\end{array}$ & $\begin{array}{l}\text { Virgin } \\
\text { polymer }\end{array}$ & $\begin{array}{l}\text { Composite } \\
(\% \text { increase })\end{array}$ & Ref. \\
\hline HDPE & GNP (8.0) & Melt & 0.42 & $0.64(52 \%)$ & 74 \\
LLDPE & TRG (3.0) & Melt & 0.20 & $0.52(160 \%)$ & 89 \\
PP & GNP (50.0) & Melt & 0.22 & $1.20(>400)$ & 92
\end{tabular}

${ }^{a}$ Graphene wt $\%$ at which maximum thermal conductivity is achieved.

functionalized graphene (FG) and without modified graphene prepared by the melt blending method. The initial degradation temperature and maximum degradation temperature increased by $12{ }^{\circ} \mathrm{C}\left(388\right.$ to $400{ }^{\circ} \mathrm{C}$ ) and $66{ }^{\circ} \mathrm{C}$ (from 407 to $473{ }^{\circ} \mathrm{C}$ ) respectively for $\mathrm{iPP} / \mathrm{FG}$ nanocomposites, even at very low loading ( $0.1 \mathrm{wt} \%)$ of $\mathrm{FG}$ as compared to iPP/graphene composites. They also observed that the crystallization temperature $\left(T_{\mathrm{c}}\right)$, in the case of both iPP/graphene and the iPP/ FG nanocomposites, increased with increasing filler content. The crystallization temperature $\left(T_{\mathrm{c}}\right)$ of iPP/FG nanocomposites increased from $109.5{ }^{\circ} \mathrm{C}$ (for virgin iPP) to $119.5^{\circ} \mathrm{C}$ (for iPP/FG composites at $0.2 \mathrm{wt} \% \mathrm{FG}$ ).

\subsection{Electrical conductivity of polyolefin/graphene composites}

In addition to the exceptional thermal and mechanical properties, graphene also possesses very high intrinsic electrical conductivity. Thus, the incorporation of small amounts of graphene can lead to a significant increase in the electrical conductivity in the host of polymer matrices. It was observed that the electrical conductivity of the insulating polymer can be increased by several orders of magnitude by the addition of a very small amount of graphene in the polymer matrices, which will help in preserving other performance properties of polymers such as thermal and mechanical properties, low melt flow viscosities, etc. Particularly, the use of graphene as a conductive additive to polyolefin is emerging as a major applications in sensors, antistatic materials in electrostatic discharge (ESD), electromagnetic interference (EMI) shielding materials and conductive coatings. The increase in electrical conductivity of the polymer matrix upon incorporation of graphene depends on many factors including the type of dispersion of graphene, aspect ratio, surface functionalization and the amount of loading. It is known that the electrical conductivity of the nanocomposites increased with increasing filler loading till a critical filler concentration value, where a dramatic increase in conductivity is observed after that the conductivity value is saturated. This critical filler concentration is called the electrical percolation threshold concentration, where the filler forms a three-dimensional conductive network within the matrix. Several studies have been carried out on the electrical conductivity of graphene based polyolefin composites (Table 3). In particular, Du et al. ${ }^{99}$ prepared an electrically conducting UHMWPE/graphene composite by the solvent assisted method; they found the electrical percolation threshold concentration (PTC) at $\sim 0.17 \mathrm{wt} \%$ graphene and maximum conductivity of $\sim 10^{-3} \mathrm{~S} \mathrm{~cm}^{-1}$ at $1.5 \mathrm{wt} \%$ of graphene loading. Following the same procedure, Zhao et al. ${ }^{81}$ reported a very low percolation threshold concentration of $0.028 \mathrm{vol} \%(\sim 0.05 \mathrm{wt} \%)$ graphene in the case of the graphene/UHMWPE composite with segregated structure prepared by solution processing with maximum conductivity value of $\sim 10^{-2} \mathrm{~S} \mathrm{~cm}^{-1}$ at $1 \mathrm{wt} \%$ of graphene loading. However, in the case of polypropylene/graphene composites, Guo et $a .^{87}$ reported a very high percolation threshold concentration of $12 \mathrm{wt} \%$ graphene loading. In another report, Dong et al. ${ }^{68}$ found the maximum electrical conductivity of $3 \times 10^{-3} \mathrm{~S} \mathrm{~cm}^{-1}$ at $4.9 \mathrm{wt} \%$ of GO in the PP/GO composite prepared via in situ Ziegler-Natta polymerization. Some other results on polyolefin composites are summarized in Table 6.

\subsection{Gas barrier properties of polyolefin/graphene composites}

The barrier properties of a polymer are very important for many packaging and protective applications such as in the food industry, pharmaceuticals and electronic devices (e.g. flexible 
Table 6 Electrical conductivity of polyolefin/graphene composites

\begin{tabular}{|c|c|c|c|c|c|}
\hline $\begin{array}{l}\text { Polymer } \\
\text { matrix }\end{array}$ & $\begin{array}{l}\text { Graphene }{ }^{a} \\
\text { (wt\%) }\end{array}$ & $\begin{array}{l}\text { Method of } \\
\text { preparation }\end{array}$ & $\begin{array}{l}\text { PTC } \\
(w t \%)\end{array}$ & $\begin{array}{l}\text { Electrical conductivity } \\
\left(\mathrm{S} \mathrm{cm}^{-1}\right)\end{array}$ & Ref. \\
\hline LLDPE- $g$-Py & TRG (4.0) & Melt & $1.3-2.2$ & $\sim 10^{-4}$ & 89 \\
\hline UHMWPE & RGO (4.0) & Solution & 0.3 & $7.1 \times 10^{-2}$ & 82 \\
\hline UHMWPE & GNS (2.0) & Solution & $\sim 0.25$ & $\sim 10^{-4}$ & 83 \\
\hline UHMWPE & GNS (10.0) & In situ & 2.5 & $10^{-3}$ & 61 \\
\hline UHMWPE & GNS (1.5) & Solution & 0.17 & $\sim 10^{-3}$ & 63 \\
\hline UHMWPE & RGO (1.0) & Solution & 0.06 & $\sim 10^{-2}$ & 81 \\
\hline PP & GO (4.9) & In situ & 1.52 & $3 \times 10^{-3}$ & 69 \\
\hline PP & ODA-f-G (1.25) & Melt & 0.63 & $\sim 10^{-5}$ & 94 \\
\hline $\mathrm{PP}$ & GnP (15.0) & Solution & 12 & $\sim 10^{-3}$ & 87 \\
\hline iPP & TRG (10.0) & Melt & $<5$ & $\sim 10^{-3}$ & 93 \\
\hline
\end{tabular}

displays). It is worth mentioning that for packaging applications, the polymer should have extremely low gas and vapour permeabilities in various environments. ${ }^{101} \mathrm{~A}$ number of methods are available for improving the barrier properties of polymeric materials along with some drawbacks due to high cost, opacity, humidity sensitivity and low mechanical strength. ${ }^{\mathbf{1 0 2}}$ Polymeric materials such as $\mathrm{PE},{ }^{\mathbf{1 0 3}} \mathrm{PP},{ }^{\mathbf{1 0 4}}$ and other matrices ${ }^{\mathbf{1 0 5}, \mathbf{1 0 6}}$ have been extensively used to coat thin film layers for low gas permeability. However, their applications are limited because of the high gas permeability, as compared to high demands for the modern packaging application. For the improvement of gas barrier properties of polymers, various nanomaterials have been used to fabricate polymer nanocomposites, where these nanomaterials will block the gas or vapour diffusion to increase the tortuosity, resulting in an extended travelling pathway of diffused gas through polymer nanocomposites. Layered nano-silicates have been extensively investigated during the last decade because of their excellent barrier properties. ${ }^{\mathbf{1 0 7 - 1 1 0}}$ However, due to their hydrophilic nature, silicate clays tend to aggregate easily because of van der Waals and electrostatic interactions during mixing in solution, as a result the barrier properties decrease.

POs, especially PE and PP, have had great commercial application in the packaging industry, being the most extensively used of all thermoplastic materials. ${ }^{\mathbf{1 1 1}}$ For the improvement of barrier properties, graphene has recently been incorporated into

Table 7 Gas permeability of polyolefin/graphene composites

\begin{tabular}{|c|c|c|c|c|c|}
\hline $\begin{array}{l}\text { Polymer } \\
\text { matrix }\end{array}$ & $\begin{array}{l}\text { Graphene }^{a} \\
\text { (wt\%) }\end{array}$ & $\begin{array}{l}\text { Method of } \\
\text { preparation }\end{array}$ & Gas & $\begin{array}{l}\text { Gas permeability } \\
(\%) \text { in } \mathrm{fm} \mathrm{Pa}^{-1} \mathrm{~s}^{-1}\end{array}$ & Ref. \\
\hline \multirow[t]{2}{*}{ LLDPE } & DA-f-G (1.0) & Solution & Nitrogen & 11.9 to $5.7(52)$ & 73 \\
\hline & & & Oxygen & 36.8 to $19.5(47)$ & \\
\hline PP & RGO (1.0) & Melt & Oxygen & 179.8 to $58.2(\sim 68)$ & 112 \\
\hline PP & GNP (6.5) & Melt & Oxygen & 220 to $202(\sim 20)$ & 92 \\
\hline
\end{tabular}

${ }^{a}$ Graphene wt $\%$ at which maximum reduction in gas permeability is achieved. polyolefin matrices as a nanofiller due its remarkable material properties..$^{73,112,113}$ It has been reported that defect free, single crystalline monolayer graphene not only gives excellent mechanical and electrical properties, but also has good gas impermeability. ${ }^{4}$ However, the synthesis of defect free monolayer graphene is still a challenge. One strategy for the use of the gas barrier properties of graphene in mass production is to use GO or RGO, which are prepared by oxidation, followed by the exfoliation and reduction of graphite (Table 7). Kuila et l. $^{73}$ reported the gas barrier $\left(\mathrm{N}_{2}\right.$ and $\left.\mathrm{O}_{2}\right)$ properties of LLDPE/DA-f-G composites. They found that the permeability of $\mathrm{N}_{2}$ and $\mathrm{O}_{2}$ gas was lower, compared to neat polymer. The oxygen permeability was reduced from 36.8 to $19.5 \mathrm{fm} \mathrm{Pa}^{-1} \mathrm{~s}^{-1}$, whereas for nitrogen it was reduced from 11.9 to $5.7 \mathrm{fm} \mathrm{Pa}^{-1} \mathrm{~s}^{-1}$ at $1 \mathrm{wt} \% \mathrm{DA}-\mathrm{G}$ and it was almost constant for the higher graphene loadings up to $5 \mathrm{wt} \%$.

Song et al. ${ }^{112}$ prepared PP/RGO nanocomposites via melt blending, which shows reduction in oxygen permeability up to $\sim 68 \%$ (179.8 to $58.2 \mathrm{fm} \mathrm{Pa}^{-1} \mathrm{~s}^{-1}$ ) at $1 \mathrm{wt} \%$ of RGO loading, which is attributed to the high aspect ratio of RGO, resulting in increased diffusion length of oxygen permeation. Kalaitzidou et al..$^{92}$ reported only $\sim 20 \%$ reduction $\left(220\right.$ to $\left.202 \mathrm{fm} \mathrm{Pa}^{-1} \mathrm{~s}^{-1}\right)$ in the oxygen permeability of PP/GNP composites at $6.5 \mathrm{wt} \%$ GNP loading. Thus, the incorporation of graphene based fillers can significantly reduce gas permeation through a polymer composite, as compared to the neat polymer. A percolating network of platelets can provide a 'tortuous path', which inhibits molecular diffusion through the matrix, thus resulting in significantly reduced permeability.

\subsection{Rheological properties of polyolefin/graphene composites}

Polymers have viscoelastic properties by nature and hence, they have distinct flow behaviour. Rheological properties are very important factors for analysing the melt flow properties of polymers and nanocomposites. The knowledge and design of the flow behaviour is essential for its processing and commercial applications in all forms of production and processing of polymers to 
manufacture either small or larger parts. This is directly related to the microstructure of the materials, interactions between polymer chains and nanofillers, aspect ratio of the nanofiller and most importantly, the dispersion state of the nanofillers. Several efforts have been made to explore the rheological properties of the polymer, which is very much responsive to the change in structure of the filled polymer nanocomposites in the low frequency range. Various polymer nanocomposites have been used to study their rheological behaviour based on carbon nanofillers (MWCNT and graphene) such as poly(methyl methacrylate), ${ }^{114-117}$ polyesters ${ }^{118,119}$ and polyolefins. ${ }^{76,79,120,121}$ Among the polyolefins/graphene composites, the rheological properties of polyethylenes/graphene composites are less explored, compared to polypropylene composites. ${ }^{87,91,122}$

The present study is mainly focused on the rheological properties of polyolefin (PE and PP)/graphene composites. Kontopoulou et $a .^{\mathbf{1 2 0}}$ studied the rheological behaviour of LLDPE nanocomposites based on TRG as the nanofiller prepared by the melt blending technique. LLDPE was grafted with pyridine for compatibility with TRG and to establish a non-covalent $\pi-\pi$ interaction between them. They found a pronounced increase in the viscoelastic properties of the composites with increased concentration of TRG loading. Recently, Khanam et al. ${ }^{121}$ reported the melt blending of LLDPE with graphene nanoplatelets (GNPs) in a twin screw extruder by varying the screw speed and GNP loading. It was observed that with increasing GNPs loading at low speed, the viscosity of the polymer increased, which indicates that more power is required for processing, whereas at higher speed there was a reduction in viscosity. However, they found that the high screw speed resulted in good dispersion of GNPs in the matrix and thus an increase in thermal stability and thermal conductivity, whereas this effect was not significant for the mechanical and electrical properties. Rastogi et al. ${ }^{79}$ studied the unique rheological properties of UHMWPE nanocomposites based on reduced graphene oxide nanosheets (rGON). They used commercial UHMWPE (C_PE) and lab made disentangled UHMWPE (Dis_PE) with GO to make composites, followed by compression moulding at varying temperatures $\left(160{ }^{\circ} \mathrm{C}\right.$ for C_PE and $125^{\circ} \mathrm{C}$ for Dis_PE). The rheological analysis of the two sets C_PE/rGON and Dis_PE/rGON nanocomposites reveals the difference in the interaction between the polymer chains of Dis_PE and rGON, as compared to the entangled C_PE. In both cases, minima in the storage modulus curve at a specific rGON concentration was seen (Fig. 7). Thus, it was concluded that strong interactions of polymer chains with rGON inhibit Dis_PE from achieving thermodynamic equilibrium in the melt state, whereas in the C_PE sample, the broader molecular weight distribution and higher adhesion of the long polymer chains to the rGON surface lowers the elastic modulus in the polymer melt.

The rheological properties of polypropylene nanocomposites with nanofillers have been studied more as compared to other polyolefins. Guo et $a l^{87}$ fabricated polypropylene graphene nanoplatelet (GNP) composites by solvent blending techniques and studied their rheological properties. The results reveal that at lower GNP loading $(<12 \mathrm{wt} \%)$, the modulus and viscosity of the PP/GNP composites were reduced, whereas at higher loading, they increased. Achaby et al. ${ }^{91}$ prepared graphene based PP composites by the melt blending technique. Rheological studies of the PP/ graphene nanocomposites showed a Maxwellian-like behaviour
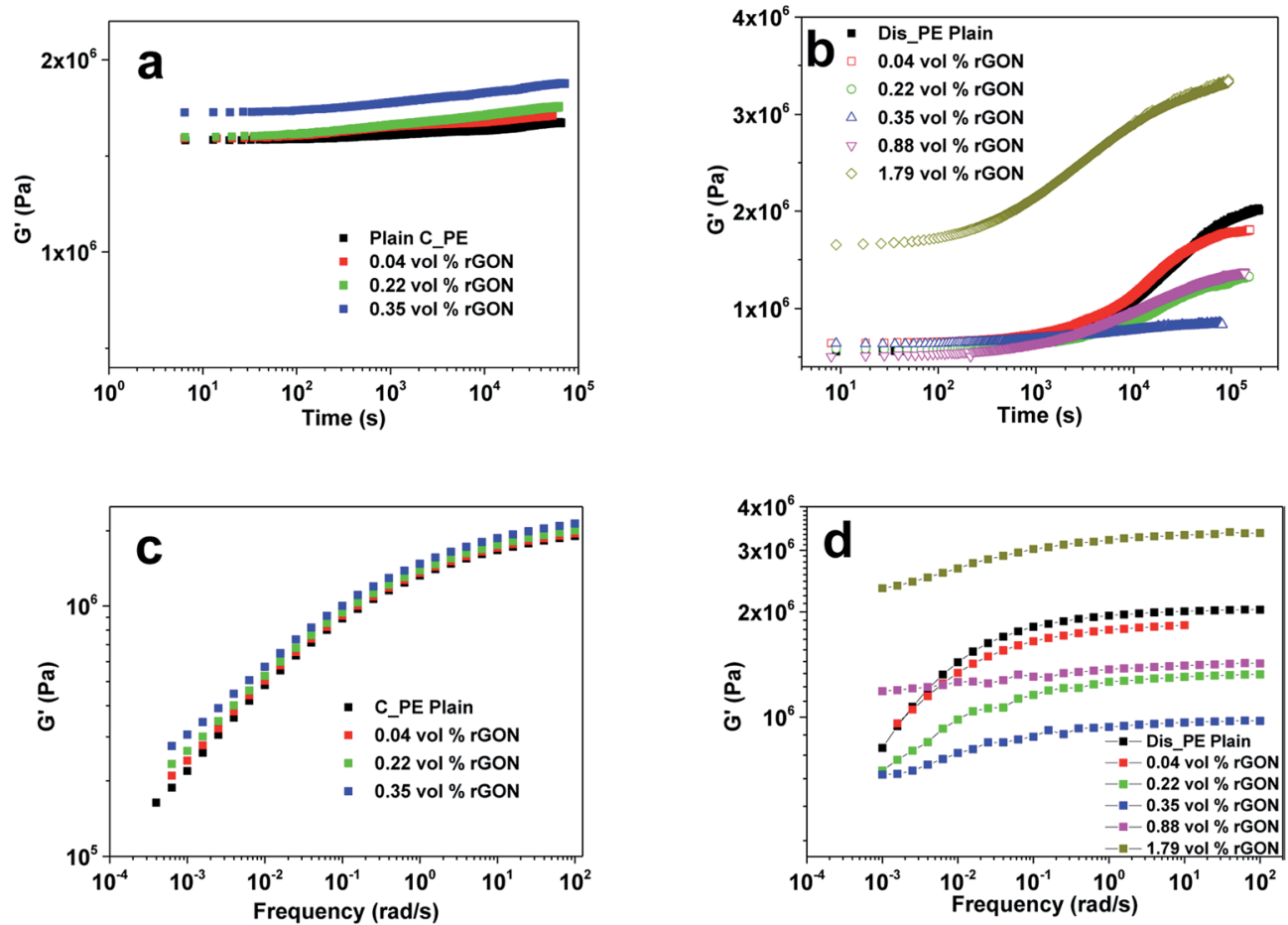

Fig. 7 Storage modulus vs. frequency graphs of (a) C_PE/rGON composites. (b) Dis_PE/rGON composites and frequency sweep graphs of (c) C_PE/rGON composites. (d) Dis_PE composites (reproduced with permission from ref. 79 copyright 2015 American Chemical Society). 
at lower graphene loadings ( $<0.5 \mathrm{wt} \%$ ) and a viscoelastic solid-like behaviour at higher graphene loading exceeding the percolation threshold limit, which lies between 0.5 to $1.0 \mathrm{wt} \%$.

\section{Future perspectives and applications}

The versatility of graphene/polyolefin nanocomposites indicates their potential for application in the automotive, aerospace, electronics and packaging industries. However, there are several challenges:

- Micromechanically produced monolayer and bilayer graphene, which are supported on $\mathrm{SiO}_{2}$ substrate, are sold at 0.5-3 British pound per $\mu \mathrm{m}^{2} .^{15}$ Graphene can be produced more economically via the reduction of GO, but it will not see practical applications until the commercial scale production of graphene is available at a lower cost.

- Another barrier to practical application is the dispersion of graphene in the polyolefin matrix and also the handling of graphene during processing. To date, the most commonly used route to produce graphene is via GO by the oxidation of graphite ${ }^{44}$ i.e. the modified Hummers' method.

- Another important factor is the adhesion between graphene and polyolefin, which is considered in designing the composite materials. We can get superior mechanical properties when graphene is strongly bonded to polymer matrix polymers. This can be done by covalently attaching alkyl groups to the graphene surface, resulting in the compatibility with the polyolefin matrices.

The outstanding properties of graphene have opened up a new age of advanced multifunctional materials. Incorporation of graphene into polyolefin matrices provides materials that could be used for many high performance engineering applications like conductive paints, EMI shielding and electrostatic discharge material, and as gas barriers in packaging application..$^{73,123,124}$ Thin layers of graphene on plastics might also be used as transparent conducting composites. The high mechanical strength of polymer/graphene nanocomposites could be utilized to make some high-end sporting goods such as tennis rackets, baseball bats, etc. The superior thermal stability of graphene based polymer composites could be utilized for the production of flame retarding materials. ${ }^{123}$ In a very recent report You et al. ${ }^{125}$ fabricated a cost effective PP/graphene nanocomposite that has inplane oriented graphene sheets by melt blending in a microcompounder, followed by biaxial stretching to make $\mathrm{PP} /$ graphene film. It was found that as a consequence of this in-plane orientation of graphene sheets, the storage modulus and conductivity of the polypropylene composite was improved as compared to virgin PP. Therefore, they suggested that this strategy can be integrated with the commercialized biaxial process to produce high quality polyolefin/graphene composite films.

\section{Conclusions}

We have reviewed the current methods of preparation, properties and potential applications of graphene and polyolefin/graphene composites. Although the polyolefin/graphene composite is still in its early stage of development, the huge potential of this material has become apparent in different fields of research such as automotive, electronic application and recently, in barrier application. The main challenge to fully exploiting graphene/ polyolefin composites is that of achieving the level of homogeneous dispersion of graphene so that maximum surface area will be available for the load transfer between filler and matrix polymer. The functionalization of the graphene surface with organic modifiers is one of the best routes to improving the dispersion as well as the stress transfer between graphene and the polyolefin matrix, which has to be carried out as per the requirements in order to provide proper bonding. However, the functionalization of the graphene surface affects the intrinsic properties of graphene; therefore, it is important to focus on different methods for non-covalent functionalization of graphene and discover a route that can improve the dispersion and compatibility without affecting the intrinsic properties.

Three major techniques, solution, melt and in situ polymerization, are used in the fabrication of graphene/polymer composites. Although solution blending produces high quality composites, melt compounding is simple, greener and provides options for the large scale production of polyolefin/graphene nanocomposites. Recently, in situ polymerization has also shown great potential in the manufacture of polyolefin/graphene nanocomposites, especially graphene based PP, LLDPE and UHMWPE composites. It is expected that the addition of graphene nanosheets to polymer matrices could act as an excellent reinforcement, but this has yet to be fully realized.

\section{Abbreviations}

$\begin{array}{ll}\text { GO } & \text { Graphene oxide } \\ \text { RGO } & \text { Reduced graphene oxide } \\ \text { CVD } & \text { Chemical vapour deposition } \\ \text { PO } & \text { Polyolefin } \\ \text { GNS } & \text { Graphene nanosheet } \\ \text { GNP } & \text { Graphene nanoplatelets } \\ \text { GNR } & \text { Graphene nanoribbons } \\ \text { TRG } & \text { Thermally reduced graphene oxide } \\ \text { MWCNT } & \text { Multiwall carbon nanotubes } \\ \text { CB } & \text { Carbon black } \\ \text { PNC } & \text { Polymer nanocomposites } \\ \text { PP } & \text { Polypropylene } \\ \text { PE } & \text { Polyethylene } \\ \text { DMF } & N, N \text {-Dimethyl formamide } \\ \text { ODCB } & \text { Ortho dichlorobenzene }\end{array}$

\section{Acknowledgements}

The authors would like to thank $\mathrm{M} / \mathrm{s}$ Reliance Industries Limited, Mumbai for giving permission to publish this paper.

\section{References}

1 J. C. Huang, Carbon black filled conducting polymers and polymer blends, Adv. Polym. Technol., 2002, 21, 299-313. 
2 M. Moniruzzaman and K. I. Winey, Polymer nanocomposites containing carbon nanotubes, Macromolecules, 2006, 39, 5194-5205.

3 M. Okamoto, Polymer/clay nanocomposites, American Scientific Publishers, Stevenson Ranch, CA, 2004, p. 8.

$4 \mathrm{~K}$. Geim and K. S. Novoselov, The rise of graphene, Nat. Mater., 2007, 6, 183-191.

5 J. W. Suk, R. D. Piner, J. An and R. S. Ruoff, Mechanical properties of monolayer graphene oxide, ACS Nano, 2010, 4, 6557-6564.

6 G. A. Snook, P. Kao and A. S. Best, Conducting-polymerbased supercapacitor devices and electrodes, J. Power Sources, 2011, 196, 1-12.

7 Z. Yin, S. Wu, X. Zhou, X. Huang, Q. Zhang, F. Boey, et al., Electrochemical deposition of $\mathrm{ZnO}$ nanorods on transparent reduced graphene oxide electrodes for hybrid solar cells, Small, 2010, 6, 307-312.

8 Z. Yin, S. Sun, T. Salim, S. Wu, X. Huang and Q. He, Organic photovoltaic devices using highly flexible reduced graphene oxide films as transparent electrodes, ACS Nano, 2010, 4, 5263-5268.

9 F. Yavari and N. Koratkar, Graphene-based chemical sensors, J. Phys. Chem. Lett., 2012, 3, 1746-1753.

10 S. K. Mishra, S. N. Tripathi, V. Choudhary and B. D. Gupta, SPR based fibre optic ammonia gas sensor utilizing nanocomposite film of PMMA/reduced graphene oxide prepared by in situ polymerization, Sens. Actuators, B, 2014, 199, 190-200.

11 A. U. Chaudhry, V. Mittal and M. I. Hashmi, A quick review for rheological properties of polyolefin composites, Sindh Univ. Res. J., Sci. Ser., 2012, 44, 75-84.

12 K. R. Sarma, A. B. Mathur, R. V. Jasra, S. Padmanabhan, S. Shashikant and V. K. Patel, Process for synthesis of ethylene polymers, US 2014/0221588 A1, 2014.

13 B. M. Cromer, S. Scheel, G. A. Luinstra, E. B. Coughlin and A. J. Lesser, In situ polymerization of isotactic polypropylene-nanographite nanocomposites, Polymer, 2015, 80, 275-281.

14 W. K. Chee, H. N. Lim, N. M. Huang and I. Harrison, Nanocomposites of graphene/polymers: a review, $R S C$ $A d v ., 2015$, 5, 68014-68051.

15 H. Kim, A. A. Abdala and C. W. Macosko, Graphene/ polymer nanocomposites, Macromolecules, 2010, 43, 65156530.

16 J. R. Potts, D. R. Dreyer, C. W. Bielawski and R. S. Ruoff, Graphene-based polymer nanocomposites, Polymer, 2011, 52, 5-25.

17 R. Verdejo, M. M. Bernal, L. J. Romasanta and M. A. LopezManchado, Graphene filled polymer nanocomposites, $J$. Mater. Chem., 2011, 21, 3301-3310.

18 R. K. Layek and A. K. Nandi, A review on synthesis and properties of polymer functionalized graphene, Polymer, 2013, 54, 5087-5103.

19 K. S. Novoselov, A. K. Geim, S. V. Morozov, D. Jiang, Y. Zhang and S. V. Dubonos, Electric field effect in atomically thin carbon films, Science, 2004, 306, 666-669.
20 X. Wang, H. You, F. Liu, M. Li, L. Wan, S. Li, et al., Largescale synthesis of few-layered graphene using CVD, Chem. Vap. Deposition, 2009, 15, 53-56.

21 S. C. Xu, B. Y. Man, S. Z. Jiang, C. S. Chen, C. Yang and M. Liu, Direct synthesis of graphene on $\mathrm{SiO}_{2}$ substrates by chemical vapor deposition, CrystEngComm, 2013, 15, 1840-1844.

22 N. Li, Z. Wang, K. Zhao, Z. Shi, Z. Gu and S. Xu, Large scale synthesis of $\mathrm{N}$-doped multi-layered graphene sheets by simple arc-discharge method, Carbon, 2010, 48, 255-259.

23 K. S. Subrahmanyam, L. S. Panchakarla, A. Govindaraj and C. N. R. Rao, Simple method of preparing graphene flakes by an arc-discharge method, J. Phys. Chem. C, 2009, 113, 4257-4259.

24 E. Rollings, G. H. Gweon, S. Y. Zhou, B. S. Mun, J. L. McChesney and B. S. Hussain, Synthesis and characterization of atomically thin graphite films on a silicon carbide substrate, J. Phys. Chem. Solids, 2006, 67, 2172-2177.

25 W. A. de Heer, C. Berger, X. Wu, P. N. First, E. H. Conrad and X. Li, Epitaxial graphene, Solid State Commun., 2007, 143, 92-100.

26 D. V. Kosynkin, A. L. Higginbotham, A. Sinitskii, J. R. Lomeda, A. Dimiev and B. K. Price, Longitudinal unzipping of carbon nanotubes to form graphene nanoribbons, Nature, 2009, 458, 872-876.

27 A. Hirsch, Unzipping carbon nanotubes: A peeling method for the formation of graphene nanoribbons, Angew. Chem., Int. Ed., 2009, 48, 6594-6596.

28 S. Mohammadi, Z. Kolahdouz, S. Darbari, S. Mohajerzadeh and N. Masoumi, Graphene formation by unzipping carbon nanotubes using a sequential plasma assisted processing, Carbon, 2013, 52, 451-463.

29 D. Chen, L. Tang and J. Li, Graphene-based materials in electrochemistry, Chem. Soc. Rev., 2010, 39, 3157-3180.

30 S. Park, J. An, J. R. Potts, A. Velamakanni, S. Murali and R. S. Ruoff, Hydrazine-reduction of graphite and graphene oxide, Carbon, 2011, 49, 3019-3023.

31 M. T. C. J. Sun, N. Lindvall, K. B. Teo and A. Yurgen, Noncatalytic chemical vapor deposition of graphene on high-temperature substrates for transparent electrodes, Appl. Phys. Lett., 2012, 100, 022102.

32 N. L. J. Sun, M. T. Cole, B. K. Teo and A. Yurgen, Large-area uniform graphene-like thin films grown by chemical vapour deposition directly on silicon nitride, Appl. Phys. Lett., 2011, 98, 252107.

33 M. H. Rümmeli, A. Bachmatiuk, A. Scott, F. Börrnert, J. H. Warner and V. Hoffman, Direct low-temperature nanographene CVD synthesis over a dielectric insulator, ACS Nano, 2010, 4, 4206-4210.

34 L. Jiao, L. Zhang, X. Wang, G. Diankov and H. Dai, Narrow graphene nanoribbons from carbon nanotubes, Nature, 2009, 458, 877-880.

35 B. C. Brodie, On the atomic weight of graphite, Philos. Trans. R. Soc. London, 1859, 149, 249-259.

36 L. Staudenmaier, Verfahren zur Darstellung der Graphitsäure, Ber. Dtsch. Chem. Ges., 1898, 31, 1481-1487. 
37 W. S. Hummers and R. E. Offeman, Preparation of graphitic oxide, J. Am. Chem. Soc., 1958, 80, 1339.

38 S. N. Tripathi, P. Saini, D. Gupta and V. Choudhary, Electrical and mechanical properties of PMMA/reduced graphene oxide nanocomposites prepared via in situ polymerization, J. Mater. Sci., 2013, 48, 6223-6232.

39 A. Lerf, H. He, M. Forster and J. Klinowski, Structure of graphite oxide revisited, J. Phys. Chem. B, 1998, 102, 44774482.

40 H. He, J. Klinowski, M. Forster and A. Lerf, A new structural model for graphite oxide, Chem. Phys. Lett., 1998, 287, 5356.

41 S. Stankovich, D. A. Dikin, R. D. Piner, K. A. Kohlhaas, A. Kleinhammes and Y. Jia, Synthesis of graphene-based nanosheets via chemical reduction of exfoliated graphite oxide, Carbon, 2007, 45, 1558-1565.

42 S. Stankovich, D. A. Dikin, G. H. B. Dommett, K. M. Kohlhaas, E. J. Zimney and E. A. Stach, Graphenebased composite materials, Nature, 2006, 442, 282-286.

43 E. T. Samulski, Synthesis of water soluble graphene, Nano Lett., 2008, 8, 1679-1682.

44 G. Wang, J. Yang, J. Park, X. Gou, B. Wang and H. Liu, Facile synthesis and characterization of graphene nanosheets, $J$. Phys. Chem. C, 2008, 112, 8192-8195.

45 A. Ambrosi, C. K. Chua, A. Bonanni and M. Pumera, Lithium aluminum hydride as reducing agent for chemically reduced graphene oxides, Chem. Mater., 2012, 24, 2292-2298.

46 H. C. Schniepp, J.-L. Li, M. J. McAllister, H. Sai, M. HerreraAlonso, D. H. Adamson, et al., Functionalized single graphene sheets derived from splitting graphite oxide, $J$. Phys. Chem. B, 2006, 110, 8535-8539.

47 M. J. McAllister, J.-L. Li, D. H. Adamson, H. C. Schniepp, A. A. Abdala and J. Liu, Single sheet functionalized graphene by oxidation and thermal expansion of graphite, Chem. Mater., 2007, 19, 4396-4404.

48 P. Steurer, R. Wissert, R. Thomann and R. Mülhaupt, Functionalized graphene and thermoplastic nanocomposites based upon expanded graphite oxide, Macromol. Rapid Commun., 2009, 30, 316-327.

49 D. L. Aksay, S. Korkut and R. K. Prudhomme, WO Patent 2009/134492 A2, 2009.

50 K. S. N. S. V. Morozov, M. Katsnelson, F. Schedin, D. Elias, J. Jaszczak and A. K. Geim, Giant intrinsic carrier mobilities in graphene and its bilayer, Phys. Rev. Lett., 2008, 100, 016602.

51 X. Du, I. Skachko, A. Barker and E. Y. Andrei, Approaching ballistic transport in suspended graphene, Nat. Nanotechnol., 2008, 3, 491-495.

52 F. V. Kusmartsev, M. P. Pierpoint and K. C. Yung, Application of graphene within optoelectronic devices and transistors, 2014, arXiv:14060809.

53 C. Lee, X. Wei, J. W. Kysar and J. Hone, Measurement of the elastic properties and intrinsic strength of monolayer graphene, Science, 2008, 321, 385-388.
54 A. A. Balandin, S. Ghosh, W. Bao, I. Calizo, D. Teweldebrhan and F. Miao, Superior thermal conductivity of single-layer graphene, Nano Lett., 2008, 8, 902-907.

55 J. S. Bunch, S. S. Verbridge, J. S. Alden, A. M. van der Zande, J. M. Parpia and H. G. Craighead, Impermeable atomic membranes from graphene sheets, Nano Lett., 2008, 8, 2458-2462.

56 H. Podall, W. E. Foster and A. P. Giraitis, Catalytic graphite inclusion compounds. Potassium graphite as a polymerization catalyst, J. Org. Chem., 1958, 23, 82-85.

57 L. R. Bunnell, Method for producing thin graphite flakes with large aspect ratio, U.S. Pat., No. 5186919, Battelle Memorial Institute, 1993.

58 A. Tchernook, M. Krumova, F. J. Tolle, R. Mulhaupt and S. Mecking, Composites from aqueous polyethylene nanocrystal/graphene dispersions, Macromolecules, 2014, 47, 3017-3021.

59 K. R. Sarma, R. V. Jasra, K. Kannan, A. B. Mathur, V. K. Patel and Y. P. Patil, Immobilization of single site catalyst on inorganic oxide support for preparation of UHMWPE, US Pat. 9260538 B2, 2016.

60 K. R. Sarma, A. B. Mathur, R. V. Jasra, S. Padamanabhan, S. Shashikant and V. K. Patel, Process for synthesis of ethylene polymers, US Pat. 9175108 B2, 2015.

61 S. Rastogi, L. Kurelec, D. R. Lippits, J. Cuijpers, M. Wimmer and J. P. Lemstra, Novel route to fatigue-resistant fully sintered ultrahigh molecular weight polyethylene for knee prosthesis, Biomacromolecules, 2005, 6, 942-947.

62 D. Lahiri, F. Hec, M. Thiesse, A. Durygin, C. Zhan and A. Agarwal, Nanotribological behavior of graphene nanoplatelet reinforced ultrahigh molecular weight polyethylene composites, Tribol. Int., 2014, 70, 165-169.

63 C. S. Li, M. S. Zhan, X. C. Huang and H. Zhou, Degradation behavior of ultra-high molecular weight polyethylene fibers under artificial accelerated weathering, Polym. Test., 2012, 31, 938-943.

64 A. Ramazani, A. Kheradmand, F. Khorasheh, M. Baghalha and H. Bahrami, Effects of nano graphene oxide as support on the product properties and performance of Ziegler-Natta catalyst in production of UHMWPE, Polym. Adv. Technol., 2015, 26, 315-321.

65 M. Stürzel, M. Enders and R. Mulhaupt, Novel graphene UHMWPE nanocomposites prepared by polymerization filling using single-site catalysts supported on functionalized graphene nanosheet dispersions, Macromolecules, 2012, 45, 6878-6887.

66 S. Kanagaraj, Polymer nanotube nanocomposites synthesis, properties and applications, Scrivener Publishing LLC, USA, 2010, pp. 113-136.

67 T. Kuilaa, B. Sambhu, Y. Dahu, N. H. Kim, B. Saswata and J. H. Lee, Recent advances in graphene based polymer composites, Prog. Polym. Sci., 2010, 35, 1350-1375.

68 Y. Huang, Y. Qin, Y. Zhou, H. Niu, Z. Z. Yu and J.-Y. Dong, Polypropylene/graphene oxide nanocomposites prepared by in situ Ziegler-Natta polymerization, Chem. Mater., 2010, 22, 4096-4102. 
69 M. A. Milani, D. González, R. Quijada, D. S. Azambuja and G. B. Galland, PP/graphene nanosheet nanocomposites by in situ polymerization: Synthesis, characterization and fundamental properties, Compos. Sci. Technol., 2013, 84, 1-7.

70 S. Zhao, F. Chen, Y. Huang, J.-Y. Dong and C. C. Han, Crystallization behaviors in the isotactic polypropylene/ graphene composites, Polymer, 2014, 55, 4125-4135.

71 S. Zhao, F. Chen, Y. Huang, J.-Y. Dong and C. C. Han, Interpenetrating network formation in isotactic $\mathrm{PP} /$ graphene composites, Polymer, 2013, 54, 3680-3690.

72 D. Wang, X. Zhang, J.-W. Zha, J. Zhao, Z.-M. Dang and G.-H. Hu, Dielectric properties of reduced graphene oxide/ polypropylene composites with ultralow percolation threshold, Polymer, 2013, 54, 1916-1922.

73 T. Kuila, S. Bose, A. K. Mishra, P. Khanra, N. H. Kim and J. H. Lee, Effect of functionalized graphene on the physical properties of linear low density polyethylene nanocomposites, Polym. Test., 2012, 31, 31-38.

74 R. Asmatulu, W. S. Khan, R. J. Reddy and M. Ceylan, Synthesis and analysis of injection-molded nanocomposites of recycled high-density polyethylene incorporated with graphene nanoflakes, Polym. Compos., 2015, 36, 1565-1573.

75 Y. Lin, J. Jin and M. Song, Preparation and characterisation of covalent polymer functionalized graphene oxide, $J$. Mater. Chem., 2011, 21, 3455-3461.

76 M. El Achaby and A. Qaiss, Processing and properties of polyethylene reinforced by graphene nanosheets and carbon nanotubes, Mater. Des., 2013, 44, 81-89.

77 P. Wei and S. Bai, Fabrication of a high-density polyethylene/graphene composite with high exfoliation and high mechanical performance via solid-state shear milling, RSC Adv., 2015, 5, 93697-93705.

78 S. Suner, R. Joffe, J. L. Tipper and N. Emami, Ultra high molecular weight polyethylene/graphene oxide nanocomposites: Thermal, mechanical and wettability characterisation, Composites, Part B, 2015, 78, 185-191.

79 K. Liu, S. Ronca, E. A. Reyes, G. Forte and S. Rastogi, Unique rheological response of ultrahigh molecular weight polyethylenes in the presence of reduced graphene oxide, Macromolecules, 2015, 48, 131-139.

80 H. Pang, T. Chen, G. Zhang, B. Zeng and Z.-M. Li, An electrically conducting polymer/graphene composite with a very low percolation threshold, Mater. Lett., 2010, 64, 2226-2229.

81 H. L. Hu, G. Zhang, L. Xiao, H. Wang, Q. Zhang and Z. Zhao, Preparation and electrical conductivity of graphene/ ultrahigh molecular weight polyethylene composites with a segregated structure, Carbon, 2012, 50, 4596-4599.

82 A. Bhattacharyya, S. Chen and M. Zhu, Graphene reinforced ultra high molecular weight polyethylene with improved tensile strength and creep resistance properties, eXPRESS Polym. Lett., 2014, 8, 74-84.

83 B. Wang, H. Li, L. Li, P. Chen, Z. Wang and Q. Gu, Electrostatic adsorption method for preparing electrically conducting ultrahigh molecular weight polyethylene/ graphene nanosheets composites with a segregated network, Compos. Sci. Technol., 2013, 89, 180-185.

84 J. A. Puértolas and S. M. Kurtz, Evaluation of CNTs and graphene as reinforcements for UHMWPE based composites in arthroplastic applications: a review, $J$. Mech. Behav. Biomed. Mater., 2014, 39, 129-145.

85 H. Kim, S. Kobayashi, M. A. Abdur Rahim, M. J. Zhang, A. A. Abdala and C. W. Macosko, Graphene/polyethylene nanocomposites: effect of polyethylene functionalization and blending methods, Polymer, 2011, 52, 1837-1846.

86 P. Song, Z. Cao, Y. Cai, L. Zhao, Z. Fang and S. Fu, Fabrication of exfoliated graphene-based polypropylene nanocomposites with enhanced mechanical and thermal properties, Polymer, 2011, 52, 4001-4010.

87 Y. Li, J. Zhu, S. Wei, J. Ryu, L. Sun and Z. Guo, Poly(propylene)/ graphene nanoplatelet nanocomposites: melt rheological behavior and thermal, electrical, and electronic properties, Macromol. Chem. Phys., 2011, 212, 1951-1959.

88 W. Hu, J. Zhan, X. Wang, N. Hong, B. Wang, L. Song, A. A Stec, T. R. Hull and J. Wang, Effect of functionalized GO with hyper-branched flame retardant on flammability and thermal stability of cross-linked PE, Ind. Eng. Chem. Res., 2014, 53, 3073-3083.

89 A. Vasileiou, M. Kontopoulou and A. Docoslis, A noncovalent compatibilization approach to improve the filler dispersion and properties of polyethylene/graphene composites, ACS Appl. Mater. Interfaces, 2014, 6, 1916-1925.

90 F. Qiu, Y. Hao, X. Li, B. Wang and M. Wang, Functionalized graphene sheets filled isotactic polypropylene nanocomposites, Composites, Part B, 2015, 71, 175-183.

91 M. E. Achaby, F.-E. Arrakhiz, S. Vaudreuil, A. K. Qaiss and O. Fassi-Fehri, Mechanical, thermal, and rheological properties of graphene-based polypropylene nanocomposites prepared by melt mixing, Polym. Compos., 2012, 33, 733-744.

92 K. Kalaitzidou, H. Fukushima and L. T. Drzal, Multifunctional polypropylene composites produced by incorporation of exfoliated graphite nanoplatelets, Carbon, 2007, 45, 1446-1452.

93 P. Steurer, R. Wissert, R. Thomann and R. Mulhaupt, Functionalized graphenes and thermoplastic nanocomposites based upon expanded graphite oxide, Macromol. Rapid Commun., 2009, 30, 316-327.

94 J. H. Yoon, A. M. Shanmugharaj, W. S. Choi and S. H. Ryu, Preparation and characterization of polypropylene/ functionalized graphene nanocomposites, 18th international conference on composite materials ICCM-18, S. Korea, 2011.

95 M. El Achaby and A. Qaiss, Processing and properties of polyethylene reinforced by graphene nanosheets and carbon nanotubes, Mater. Des., 2013, 44, 81-89.

96 Y. Chen, Y. Qi, Z. Tai, X. Yan, F. Zhu and Q. Xue, Preparation, mechanical properties and biocompatibility of graphene oxide/ultrahigh molecular weight polyethylene composites, Eur. Polym. J., 2012, 48, 1026-1033.

97 L. M. Veca, M. J. Meziani, W. Wang, X. Wang, F. Lu, P. Zhang, et al., Carbon nanosheets for polymeric 
nanocomposites with high thermal conductivity, $A d v$. Mater., 2009, 21, 2088-2092.

98 A. Yu, P. Ramesh, M. E. Itkis, E. Bekyarova and R. C. Haddon, Graphite nanoplatelet-epoxy composite thermal interface materials, J. Phys. Chem. C, 2007, 111, 7565-7569.

99 J. Du, L. Zhao, Y. Zeng, L. Zhang, P. Liu and C. Liu, Comparison of electrical properties between MWCNT and graphene nanosheet/high density polyethylene composites with a segregated network structure, Carbon, 2011, 49, 1094-1100.

100 P.-G. Ren, Y. Y. Di, Q. Zhang, L. Li and H. Pang, Composites of ultrahigh-molecular-weight polyethylene with graphene sheets and MWCNTs with segregated network structure: preparation and properties, Macromol. Mater. Eng., 2012, 297, 437-443.

101 B. M. Yoo, H. J. Shin, H. W. Yoon and H. B. Park, Graphene and graphene oxide and their uses in barrier polymers, $J$. Appl. Polym. Sci., 2014, 131, 1-23.

$102 \mathrm{~J}$. Lange and Y. Wyser, Recent innovations in barrier technologies for plastic packaging: a review, Packag. Technol. Sci., 2003, 16, 149-158.

103 D. Klepac, M. Scetar, M. Kurek, P. E. Mallon, A. S. Luyt, K. Galic and S. Valic, Oxygen permeability, electron spin resonance, differential scanning calorimetry and positron annihilation lifetime spectroscopy studies of uniaxially deformed linear low-density polyethylene film, Polym. Int., 2013, 62, 474-481.

104 I. Nagai, S. Tanaka and M. Asakura, EP19960113333, 1996. 105 L. K. Massey, Permeability properties of plastics and elastomers: a guide to packaging and barrier materials, Plastics Design Library/William Andrew Publishing, 2003.

106 Y. Hu, V. Prattipati, S. Mehta, D. Schiraldi, A. Hiltner and E. Baer, Improving gas barrier of PET by blending with aromatic polyamides, Polymer, 2005, 46, 2685-2698.

107 M. Pannirselvam, Oxygen barrier property of polypropylene-polyether treated clay nanocomposite, eXPRESS Polym. Lett., 2008, 2, 429-439.

108 J. M. Herrera-Alonso, E. Marand, J. C. Little and S. S. Cox, Transport properties in polyurethane/clay nanocomposites as barrier materials: Effect of processing conditions, J. Membr. Sci., 2009, 337, 208-214.

109 A. Liu, A. Walther, O. Ikkala, L. Belova and L. A. Berglund, Clay nanopaper with tough cellulose nanofiber matrix for fire retardancy and gas barrier functions, Biomacromolecules, 2011, 12, 633-641.

110 S. Nazarenko, P. Meneghetti, P. Julmon, B. G. Olson and S. Qutubuddin, Gas barrier of polystyrene montmorillonite clay nanocomposites: effect of mineral layer aggregation, $J$. Polym. Sci., Part B: Polym. Phys., 2007, 45, 1733.

111 J. P. G. Villaluenga and B. Seoane, Influence of drawing on gas transport mechanism in LLDPE films, Polymer, 1998, 39, 3955-3965.

112 P. Song, Y. M. Yu, T. Zhang, S. Y. Fu, Z. P. Fang and Q. Wu, Permeability, viscoelasticity, and flammability performances and their relationship to polymer nanocomposites, Ind. Eng. Chem. Res., 2012, 51, 72557263.
113 J. Wang, C. Xu, H. Hu, L. Wan, R. Chen, H. Zheng, F. Liu and $\mathrm{X}$. Wang, Synthesis, mechanical, and barrier properties of LDPE/graphene nanocomposites using vinyl triethoxysilane as a coupling agent, J. Nanopart. Res., 2011, 13, 869-878.

114 S. N. Tripathi, S. Singh, R. S. Malik and V. Choudhary, Effect of multiwalled carbon nanotubes on the properties of poly(methyl methacrylate) in PMMA/CNT nanocomposites, Macromol. Symp., 2014, 341, 75-89.

115 C. McClory, T. McNally, M. Baxendale, P. Pötschke, W. Blau and $\mathrm{M}$. Ruether, Electrical and rheological percolation of PMMA/MWCNT nanocomposites as a function of CNT geometry and functionality, Eur. Polym. J., 2010, 46, 854-868.

116 C. Mao, Y. Zhu and W. Jiang, Design of electrical conductive composites: tuning the morphology to improve the electrical properties of graphene filled immiscible polymer blends, ACS Appl. Mater. Interfaces, 2012, 4, 5281-5286.

117 S. N. Tripathi, R. S. Malik and V. Choudhary, Melt rheology and thermomechanical behaviour of poly(methyl methacrylate)/reduced graphene oxide nanocomposites, Polym. Adv. Technol., 2015, 26, 1558-1566.

118 G. Hu, C. Zhao, S. Zhang, M. Yang and Z. Wang, Low percolation thresholds of electrical conductivity and rheology in poly(ethylene terephthalate) through the networks of multi-walled carbon nanotubes, Polymer, 2006, 47, 480-488.

119 A. Gupta and V. Choudhary, Rheological and mechanical properties of multiwalled carbon nanotubes-reinforced poly(trimethylene terephthalate) composites, J. Mater. Sci., 2013, 48, 3347-3356.

120 A. Vasileiou, A. Docoslis and M. Kontopoulou, A comparison of LLDPE-based nanocomposites containing graphene and multi-walled carbon nanotubes, AIP Conf. Proc., 2015, 1664, 070017, DOI: 10.1063/1.4918452.

121 P. N. Khanam, M. A. AlMaadeed, M. Ouederni, E. H. Jones, B. Mayoral, A. Hamilton and D. Sun, Melt processing and properties of linear low density polyethylene graphene nanoplatelet composites, Vacuum, 2016, 130, 63-71.

122 H. Bensalah, K. Gueraoui, H. Essabir, D. Rodrigue, R. Bouhfid and A. K. Qaiss, Mechanical, thermal, and rheological properties of polypropylene hybrid composites based clay and graphite, J. Compos. Mater., 2017, DOI: 10.1177/0021998317690597.

123 P. Song, Y. M. Yu, T. Zhang, S. Y. Fu, Z. P. Fang and Q. Wu, Permeability, viscoelasticity, and flammability performances and their relationship to polymer nanocomposites, Ind. Eng. Chem. Res., 2012, 51, 7255-7263.

124 J. Wang, C. Xu, H. Hu, L. Wan, R. Chen, H. Zheng, F. Liu and X. Wang, Synthesis, mechanical, and barrier properties of LDPE/graphene nanocomposites using vinyl triethoxysilane as a coupling agent, J. Nanopart. Res., 2011, 13, 869-878.

125 F. You, X. Li, L. Zhang, D. Wang, C.-Y. Shic and Z.-M. Dang, Polypropylene/poly(methyl methacrylate)/graphene composites with high electrical resistivity anisotropy via sequential biaxial stretching, $R S C A d v .$, 2017, 7, 6170-6178. 